\title{
Review
}

\section{Novel Applications of Microextraction Techniques Focused on Biological and Forensic Analyses}

\author{
Cristian D'Ovidio ${ }^{1}$, Martina Bonelli ${ }^{1}$, Enrica Rosato ${ }^{2}$, Angela Tartaglia ${ }^{2}$, Halil İbrahim Ulusoy ${ }^{3}(\mathbb{D}$, \\ Victoria Samanidou ${ }^{4}\left(\mathbb{D}\right.$, Kenneth G. Furton ${ }^{5}{ }^{\circ}$, Abuzar Kabir ${ }^{5,6}{ }^{\oplus}$, Imran Ali ${ }^{7,8} \mathbb{C D}^{\circ}$, Fabio Savini ${ }^{9}$, \\ Marcello Locatelli ${ }^{2, *(\mathbb{C})}$ and Ugo de Grazia ${ }^{10}(\mathbb{C}$
}

\section{check for} updates

Citation: D'Ovidio, C.; Bonelli, M.; Rosato, E.; Tartaglia, A.; Ulusoy, H.İ.; Samanidou, V.; Furton, K.G.; Kabir, A.; Ali, I.; Savini, F.; et al. Novel Applications of Microextraction Techniques Focused on Biological and Forensic Analyses. Separations 2022, 9, 18. https://doi.org/ 10.3390 /separations 9010018 Academic Editor: Georgios Theodoridis

Received: 17 December 2021 Accepted: 13 January 2022

Published: 15 January 2022

Publisher's Note: MDPI stays neutral with regard to jurisdictional claims in published maps and institutional affiliations.

Copyright: (C) 2022 by the authors. Licensee MDPI, Basel, Switzerland. This article is an open access article distributed under the terms and conditions of the Creative Commons Attribution (CC BY) license (https:// creativecommons.org/licenses/by/ $4.0 /)$.
1 Department of Medicine and Aging Sciences, University of Chieti-Pescara "G. d'Annunzio", Section of Legal Medicine, 66100 Chieti, Italy; cristian.dovidio@unich.it (C.D.); martina.bonelli@unich.it (M.B.)

2 Department of Pharmacy, University of Chieti-Pescara “G. d'Annunzio", Via dei Vestini 31, 66100 Chieti, Italy; enrica.rosato@unich.it (E.R.); angela.tartaglia@unich.it (A.T.)

3 Department of Analytical Chemistry, Faculty of Pharmacy, Cumhuriyet University, Sivas 58140, Turkey; hiulusoy@yahoo.com

4 Laboratory of Analytical Chemistry, Department of Chemistry, Aristotle University of Thessaloniki, 54124 Thessaloniki, Greece; samanidu@chem.auth.gr

5 Department of Chemistry and Biochemistry, International Forensic Research Institute, Florida International University, 11200 SW 8th St, Miami, FL 33199, USA; furtonk@fiu.edu (K.G.F.); akabir@fiu.edu (A.K.)

6 Department of Pharmacy, Faculty of Allied Health Science, Daffodil International University, Dhaka 1207, Bangladesh

7 Department of Chemistry, College of Sciences, Taibah University, Al-Medina Al-Munawara 41477, Saudi Arabia; drimran.chiral@gmail.com

8 Department of Chemistry, Jamia Millia Islamia, Jamia Nagar, New Delhi 110025, India

9 Pharmatoxicology Laboratory-Hospital "Santo Spirito", Via Fonte Romana 8, 65124 Pescara, Italy; fabio.savini@ausl.pe.it

10 Laboratory of Neurological Biochemistry and Neuropharmacology, Fondazione IRCCS Istituto Neurologico Carlo Besta, Via Celoria 11, 20133 Milan, Italy; Ugo.DeGrazia@istituto-besta.it

* Correspondence: marcello.locatelli@unich.it

\begin{abstract}
In recent years, major attention has been focused on microextraction procedures that allow high recovery of target analytes, regardless of the complexity of the sample matrices. The most used techniques included liquid-liquid extraction (LLE), solid-phase extraction (SPE), solid-phase microextraction (SPME), dispersive liquid-liquid microextraction (DLLME), microextraction by packed sorbent (MEPS), and fabric-phase sorptive extraction (FPSE). These techniques manifest a rapid development of sample preparation techniques in different fields, such as biological, environmental, food sciences, natural products, forensic medicine, and toxicology. In the biological and forensic fields, where a wide variety of drugs with different chemical properties are analyzed, the sample preparation is required to make the sample suitable for the instrumental analysis, which often includes gas chromatography (GC) and liquid chromatography (LC) coupled with mass detectors or tandem mass detectors (MS/MS). In this review, we have focused our attention on the biological and forensic application of these innovative procedures, highlighting the major advantages and results that have been accomplished in laboratory and clinical practice.
\end{abstract}

Keywords: microextraction techniques; sample preparation; forensic toxicology; complex biological matrices; green chemistry

\section{Introduction}

Sample preparation is the most important phase of the analytical workflow due to its role in the accuracy (precision and trueness) of results obtained from the analysis. Several techniques have been developed over the years, starting from the traditional 
methods for sample preparation, such as solid-phase extraction (SPE) and liquid-liquid extraction (LLE). These procedures, widely applied in many fields, have shown some limitations, such as the use of toxic organic solvents, solvent evaporation followed by sample reconstitution, and long applications time. To eloquently address the shortcomings of classical sample preparation techniques, a new class of sample preparation techniques known as microextraction techniques have emerged during the last couple of decades with a common strategy of simplification and greenification of the sample preparation workflow.

In recent years, major attention has been focused on microextraction procedures that allow high recovery of the target analytes, even if the sample matrix is too complex. The most used techniques include liquid-phase microextraction (LPME) with its different implementations, such as single-drop microextraction (SDME), dispersive liquid-liquid microextraction (DLLME), hollow fiber liquid-phase microextraction (HF-LPME), and solidified floating organic drop microextraction (SFO-DME). In LPME, the extraction phase is based on the extractive properties of different solvents (e.g., DESs, ILs, and ferrofluids), which play the most important role in the entire process.

Other microextraction techniques include solid-phase microextraction (SPME), microextraction by packed sorbent (MEPS), and fabric-phase sorptive extraction (FPSE) [1,2]. These techniques demonstrate rapid development in different fields, such as biological, environmental, food sciences, natural products, forensic medicine, and toxicology [3].

In this review, the attention has been focused on the recently developed microextraction techniques and their applications in forensic and biological fields, highlighting the major advantages and results that have been made in laboratory and clinical practice.

The application of microextraction techniques for forensic purposes is widely distributed in various fields. These procedures are part of a major investigation process conducted for justice purposes in which the analytical laboratory data can provide answers in cases of suspected death due to the effect of illicit substances, prescribed drugs, or poisons with analysis performed on postmortem samples collected during autopsies [4-7]. Biological samples may also be collected from living persons in cases of suspected drug intoxication, for example, in road accidents with driving under the influence of substances or sports doping.

Due to the legal implications of forensic analyses, it is necessary to have qualitative and quantitative analytical procedures with high precision and trueness for a broad range of analytes and different biological matrices like blood (whole blood, blood serum, and plasma), urine, and saliva as conventional sample matrices or alternative samples like hair, nails, vitreous, cerebrospinal fluid, gallbladder content, gastric and intestinal content, and tissue fragments.

One of the greatest difficulties of toxicological sample analysis lies in the possible alteration of sample composition due to the complex postmortem processes that occur in the cadavers after the intake of drugs or poisons, such as postmortem redistribution, degradation, and contamination of the matrices. Additionally, the target analytes may be present at a very low concentration, unknown, or the subject of interference with other compounds/endogenous molecules present in the sample [8,9].

For these reasons, sample preparation and extraction procedures play an important role in enhancing the sensitivity of the analysis regardless of the instrumental technique used, generally gas and liquid chromatography coupled with mass spectrometry or tandem mass spectrometry [4]. Due to the inherent complexity of these samples, sample preparation and extraction are often the most important and critical processes for the entire analysis. SPE and LLE have also been widely used in forensic analysis, and these techniques have now been improved with the development of green analytical chemistry [10]. 


\section{Materials and Methods}

\subsection{Microextraction Techniques}

Solid-Phase Extraction (SPE)

SPE is a very common extraction technique of analytes from liquid biomatrices, based on the retention (adsorption) of target analytes on the surface of an adsorbent placed on a cartridge or disk. SPE is recognized as a greener technique compared to LLE techniques, being superior in terms of speed, extraction efficiency, sample size requirement, automation, and the possibility of online coupling with the chromatographic system. The choice of adsorbent type depends on the SPE mechanism needed for the target analyte, and consequently, the retention mechanism in the subsequent HPLC separation [11]. The most recent studies on SPE applications for forensic purposes reported several methods for the simultaneous detection of illicit drugs belonging to various classes in different complex biological matrices, following the general SPE procedure reported in Figure 1.

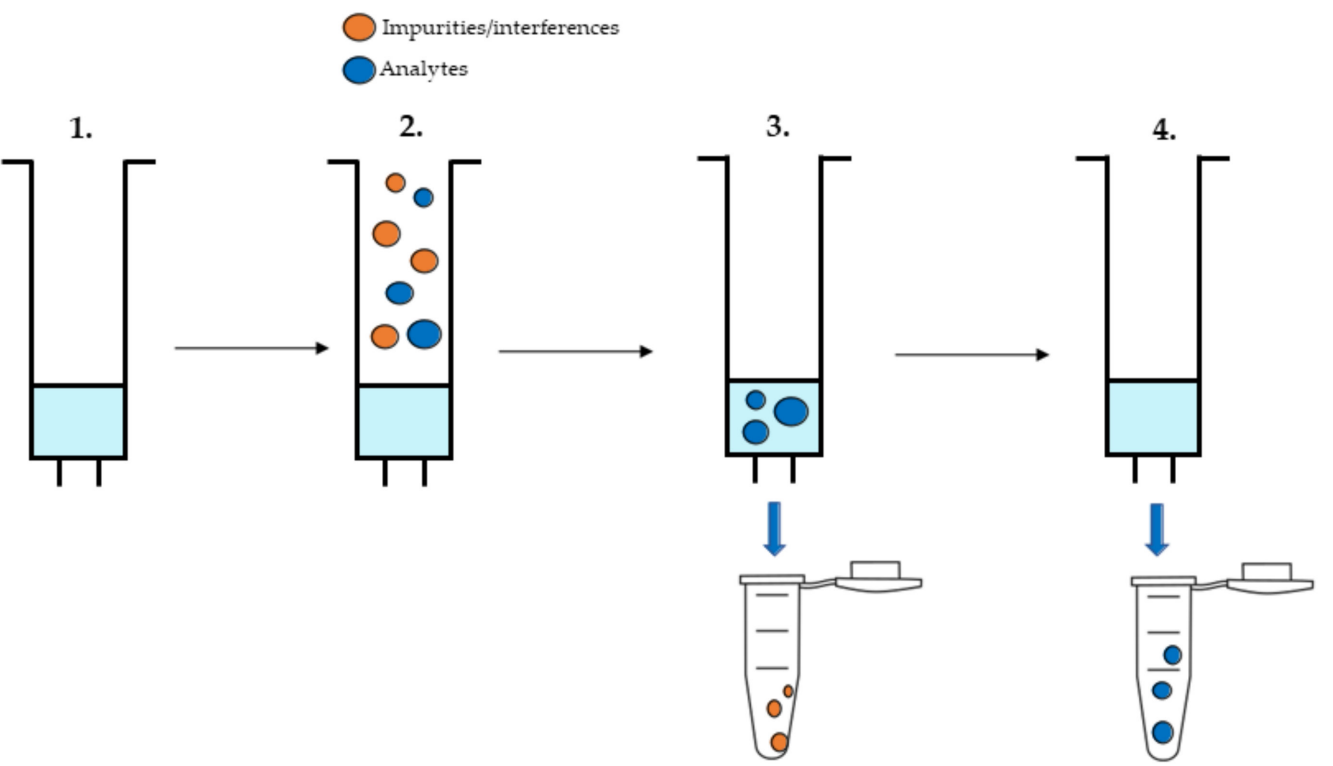

Figure 1. SPE procedure: (1) conditioning/adsorbent activation; (2) sample loading; (3) washing; (4) analytes desorption/elution.

Sofalvi et al. [12] validated a liquid chromatography-tandem mass spectrometry (LCMS/MS) method for forensic identification and quantification of fentanyl, norfentanyl (NF), and fentanyl analogs such as acetyl fentanyl (AF), 2-furanyl fentanyl, 3-methylfentanyl, and carfentanil (CF). The samples analyzed were whole blood, urine, bile, and vitreous humor derived from postmortem cases and driving under the influence of drugs cases. The samples ( $2 \mathrm{~mL}$ of whole blood) were directly aliquoted, while the vitreous humor was first centrifuged for $5 \mathrm{~min}$ at $2800 \times \mathrm{g}$ in order to avoid the classical clogging problem that stems from the SPE packing material. In this work, good performances were obtained using the $200 \mathrm{mg}$ Clean Screen ${ }^{\circledR}$ ZSDAU020 cartridge (UCT, Bristol, PA, USA). The whole procedure shows high sensitivity with limit of detections (LODs) for NF, AF, 2-Fu-F, 3-MF, and CF at $0.050 \mathrm{ng} / \mathrm{mL}$ and fentanyl at $0.50 \mathrm{ng} / \mathrm{mL}$, with bias \% values lower than $10 \%$ for all analytes. Furthermore, the intraday and interday reproducibility were $<25 \%$ and $24 \%$, respectively, and all limit of quantifications (LOQs) were $<13 \%$.

Furthermore, Kahl et al. [13] validated an ultra-high performance liquid chromatographytandem mass spectrometry (UHPLC-MS/MS) method for the simultaneous quantification of fentanyl and six fentanyl analogs such as $\beta$-hydroxythiofentanyl, acetyl fentanyl, furanyl fentanyl, carfentanil, butyryl fentanyl, and p-fluoroisobutyryl fentanyl, in postmortem biological fluids and tissues using SPE. In this case, the biological samples considered were peripheral blood, central blood, and liver and brain tissues. It is important to highlight 
that in this study, for patients hospitalized before death, samples of antemortem blood and serum were also collected and analyzed. In a glass tube, $500 \mu \mathrm{L}$ of blood, serum, or $500 \mathrm{mg}$ of homogenized tissue were buffered with $4 \mathrm{~mL}$ of sodium phosphate ( $\mathrm{pH}$ 6). All samples were vortexed for $15 \mathrm{~min}$ and then centrifuged for $10 \mathrm{~min}$ at $2300 \times g$ to remove the eventual debris for the following SPE step-by means of United Chemical Technologies Clean Screen ${ }^{\circledR}$ DAU mixed-mode (reverse-phase and ion-exchange) columns (UCT, Bristol, PA). As the general procedure applied to this analysis, the SPE was conditioned with $3 \mathrm{~mL}$ of methanol, $3 \mathrm{~mL}$ of deionized water, and $1 \mathrm{~mL}$ of $0.1 \mathrm{M}$ sodium phosphate buffer $(\mathrm{pH}$ ). The sample was added to the columns, which were then rinsed with $3 \mathrm{~mL}$ of deionized water and $1 \mathrm{~mL}$ of acetic acid. The columns were dried for $5 \mathrm{~min}$ at $120 \mathrm{psi}$ and further rinsed with $2 \mathrm{~mL}$ of hexane, $3 \mathrm{~mL}$ of hexane:ethylacetate $(50: 50, \mathrm{v}: \mathrm{v})$, and $3 \mathrm{~mL}$ of methanol. As a final step, the SPE device was then dried for an additional $3 \mathrm{~min}$ at $120 \mathrm{psi}$, and the analytes were eluted with $3 \mathrm{~mL}$ of dichloromethane:isopropanol:ammonium hydroxide (78:20:2, $\mathrm{v}: \mathrm{v}: \mathrm{v})$. The eluted sample was then dried under nitrogen flow, reconstituted with $50 \mu \mathrm{L}$ of $0.1 \%$ formic acid in water, and finally analyzed by UHPLC-MS/MS. This procedure provided high sensitivities with LOD values of $0.5 \mathrm{ng} / \mathrm{mL}$, and LOQ values of $1 \mathrm{ng} / \mathrm{mL}$ for all analytes except carfentanil (LOD $0.1 \mathrm{ng} / \mathrm{mL}$ and LOQ $0.2 \mathrm{ng} / \mathrm{mL}$ ). Furthermore, the method demonstrated acceptable bias \% within $\pm 14 \%$, intra- and inter-day precision lower than $5 \%$, and particularly an extraction efficiency $>87 \%$ for all analytes without exogenous interferences and no observable carryover phenomena.

Fogarty et al. [14] performed a similar analysis in postmortem samples (whole blood) in order to obtain a simultaneous detection of fentanyl, norfentanyl, and 17 fentanyl analogs such as furanylfentanyl, butyrylfentanyl, despropionylfentanyl (4-ANPP), methoxyacetylfentanyl, THFF, fluoro-isobutyrylfentanyl (FIBF), acrylfentanyl, p-fluorofentanyl, o-fluorofentanyl, carfentanil, $\alpha$-methylfentanyl, $\beta$-methylfentanyl, isobutyrylfentanyl, p-methylfentanyl, cyclopentylfentanyl, cyclopropylfentanyl, and $\beta$-hydroxyfentanyl. In this method, $0.5 \mathrm{~mL}$ of sample was extracted by solid-phase extraction (SPE) using $130 \mathrm{mg}$ Clean Screen ${ }^{\circledR}$ DAU (UCT, Bristol, PA, USA) extraction columns and a procedure similar to those applied by Kahl et al. [13].

This method allows identification and quantification of specific fentanyl analogs such as cyclopropylfentanyl or methoxyacetylfentanyl responsible for death with only three cases on a total of 11 samples with concentration below the limit of quantification.

Palmquist et al. [15] described a data-independent screening method using an SPE procedure optimized for the identification of 14 fentanyl analogs (fentanyl, alfentanil, acetyl fentanyl, butyryl fentanyl, remifentanil, carfentanil, cis-3-methyl-fentanyl, 4-ANPP, furanyl fentanyl, isobutyryl fentanyl, norcarfentanyl, valeryl fentanyl, norfentanyl, and sufentanyl) in a small sample of post-mortem whole blood and oral fluid using liquid chromatography quadrupole time-of-flight mass spectrometry (LC-QTOF-MS) analysis. In this work, the samples were buffered with $2.5 \mathrm{~mL}$ of phosphate buffer, centrifuged for $5 \mathrm{~min}$ at $2500 \times g$, and loaded onto SPE columns (SPEWare System 48TM CEREX1 Pressure Processor, Baldwin Park, CA, USA). The LOD ranged from 0.1 to $1 \mathrm{ng} / \mathrm{mL}$ in blood and 0.25 to $2.5 \mathrm{ng} / \mathrm{mL}$ in oral fluid. The overall results suggested the high sensitivity associated with this method.

An improvement in terms of multi-analytes, targeted analysis was published by Strayer et al. [16]. In this work, the authors described a new liquid chromatography-tandem mass spectrometry method for the multiplex detection of 24 illicitly manufactured fentanyl (IMF) analogs, metabolites, and synthetic opioids (norfentanyl, furanyl norfentanyl, remifentanil acid, butyryl norfentanyl, remifentanil, acetyl fentanyl, alfentanil, AH-7921, U-47700, acetyl fentanyl 4-methylphenethyl, acrylfentanyl, fentanyl, p-methoxyfentanyl, despropionyl fentanyl (4-ANPP), furanyl fentanyl, despropionyl p-fluorofentanyl, carfentanil, $( \pm)$-cis-3-methyl fentanyl, butyryl fentanyl, isobutyryl fentanyl, p-fluorobutyryl fentanyl, and p-fluoroisobutyryl fentanyl, sufentanyl, and valeryl fentanyl) in post-mortem whole blood. In the proposed procedure, only the isomeric forms butyryl/isobutyryl fentanyl and p-fluorobutyryl/p-fluoroisobutyryl fentanyl could not be differentiated due to isobar 
signals. The microextraction technique applied by the authors was SPE preconditioned and activated with $3.0 \mathrm{~mL}$ of methanol, washed with $3.0 \mathrm{~mL}$ of water, and conditioned to $\mathrm{pH} 6.0$ with phosphate buffer solution (PBS). Samples were loaded into the SPE columns, which were then washed with $3.0 \mathrm{~mL}$ of water, $1.0 \mathrm{~mL}$ of $1.0 \mathrm{M}$ of acetic acid, and $3.0 \mathrm{~mL}$ of methanol to remove potential matrix interferences. The cationic illicitly manufactured fentanyl (IMFs) were eluted with $3.0 \mathrm{~mL}$ of a methylene chloride/isopropanol/ammonium hydroxide mixture (78:20:2, v:v:v). The eluate was collected and evaporated, then reconstituted with $100.0 \mu \mathrm{L}$ of methanol and directly injected into LC-MS/MS. The overall analytical performances reported by the authors suggest that this procedure allows the identification of IMF analogs and metabolites in postmortem blood at sub-ng $/ \mathrm{mL}$ concentrations.

Truver et al. [17] developed and validated an analytical method for the detection and quantification of opioids, such as morphine, 6-acetylmorphine, and buprenorphine (Figure 2), including novel synthetic opioids (NSO), which have emerged into the illicit and online drug market like U-47700, U-49900, U-50488, AH-7921, MT-45, W-18, and W-15 in oral fluid (OF).
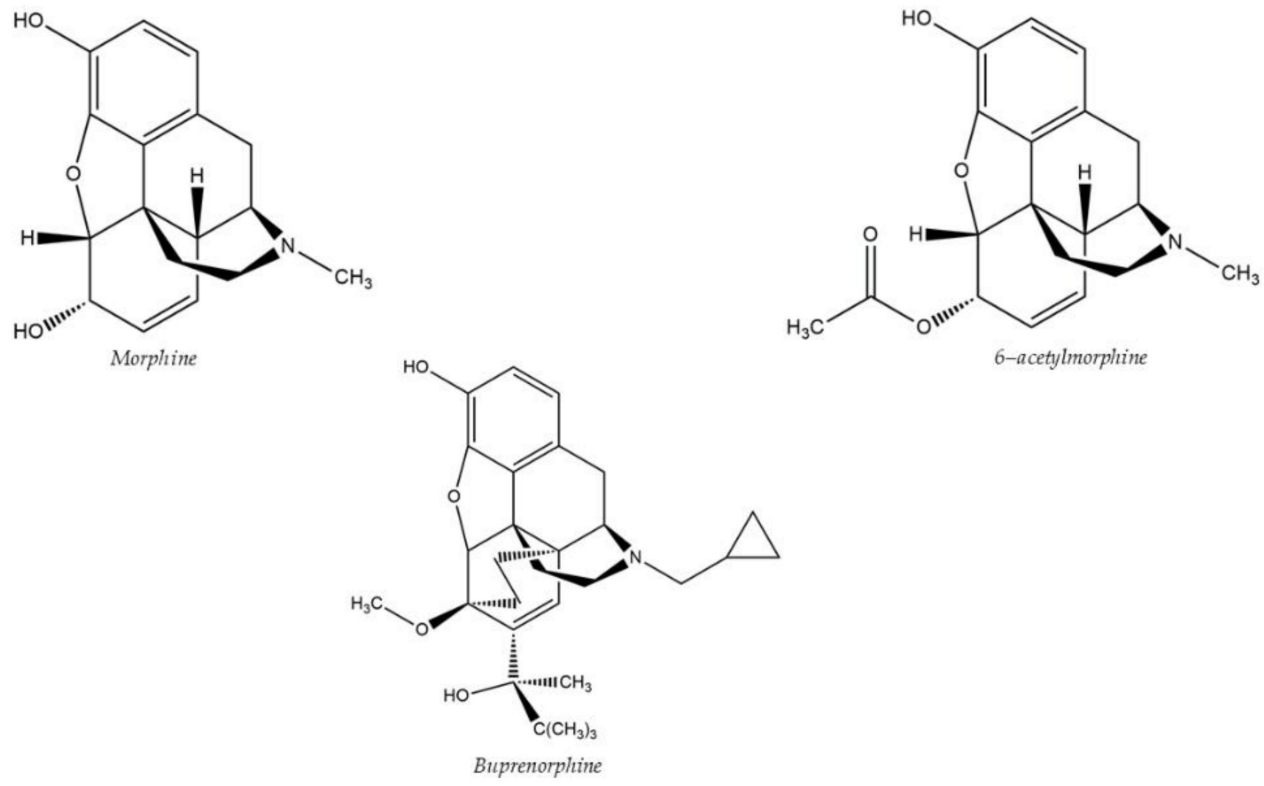

Figure 2. Chemical structures of morphine, 6-acetylmorphine, and buprenorphine.

In this work, the authors have presented the first method of extraction and quantification for $\mathrm{W}$-series drugs. In particular, SPE was performed using a CEREX-48-positivepressure manifold (SPEware, Baldwin Park, CA, USA). For the extraction process, an internal standard solution $(25 \mu \mathrm{L})$ was added to $1 \mathrm{~mL}$ of a buffer/oral fluid mixture $(750 \mu \mathrm{L}$ Quantisal buffer, $250 \mu \mathrm{L}$ drug-free oral fluid). Samples were vortexed, loaded onto SPE columns, and allowed to flow under gravity. The columns were rinsed with deionized water and acetic acid $(1 \mathrm{M})$. Cartridges were dried for $5 \mathrm{~min}$, then washed with $1 \mathrm{~mL}$ hexane. Acidic drugs were eluted using ethyl acetate. Following a $1 \mathrm{~mL}$ methanol wash, basic drugs were eluted using dichloromethane:isopropanol:ammonium hydroxide (80:20:5, v:v:v). The samples were reconstituted in $1 \mathrm{~mL}$ of mobile phase, and an aliquot of $5 \mu \mathrm{L}$ was injected onto the LC-MS/MS system. This procedure showed a limit of detection (LOD) and limit of quantification (LOQ) of $5 \mathrm{ng} / \mathrm{mL}$ and $10 \mathrm{ng} / \mathrm{mL}$, respectively. Matrix effects ranged from -21.1 to $13.7 \%$, and no carryover was observed.

Smith et al. [18] developed a method for identification and quantification of a nonfentanyl analog analgesic opioid (U-47700) and its metabolites in post-mortem whole blood samples with an optimized SPE followed by LC-MS/MS. All samples were added with $900 \mu \mathrm{L}$ of phosphate buffer ( $\mathrm{pH}$ 6.0) and then vortexed. The mixture was loaded to the SPE column and washed with $1 \mathrm{~mL}$ deionized water and $1 \mathrm{~mL}$ acetic acid. The 
column was dried at maximum pressure under nitrogen for $5 \mathrm{~min}$ and then washed with hexane, ethyl acetate, and methanol. Analytes were eluted with a $1 \mathrm{~mL}$ mixture of dichloromethane:isopropanol (80:20, v:v) with 5\% concentrated ammonium hydroxide. The elution solvent was evaporated to dryness and reconstituted in $50 \mu \mathrm{L}$ of mobile phase. Samples were then centrifuged before the LC-MS/MS for analysis. For U-47700 and Ndesmethyl-U-47700 the LOD was $0.05 \mathrm{ng} / \mathrm{mL}$ while for N,N-didesmethyl-U-477000 it was $1 \mathrm{ng} / \mathrm{mL}$. The LOQ was $0.1 \mathrm{ng} / \mathrm{mL}$ for U-47700 and N-desmethyl-U-47700, and $0.5 \mathrm{ng} / \mathrm{mL}$ for N,N-didesmethyl-U-47700. The matrix effect was $<5 \%$. The overall procedure showed good results for all target analytes with an extraction recovery $>79 \%$.

Al-Asmari [19] developed a specific and sensitive method for the analysis of $\Delta 9$ tetrahydrocannabinol (THC), 11-hydroxy- $\triangle 9$-THC (THC-OH), and 11-nor- $\triangle 9$-THC-9carboxylic acid (THC-COOH) in post-mortem cases using SPE before LC-MS/MS analysis (Figure 3).
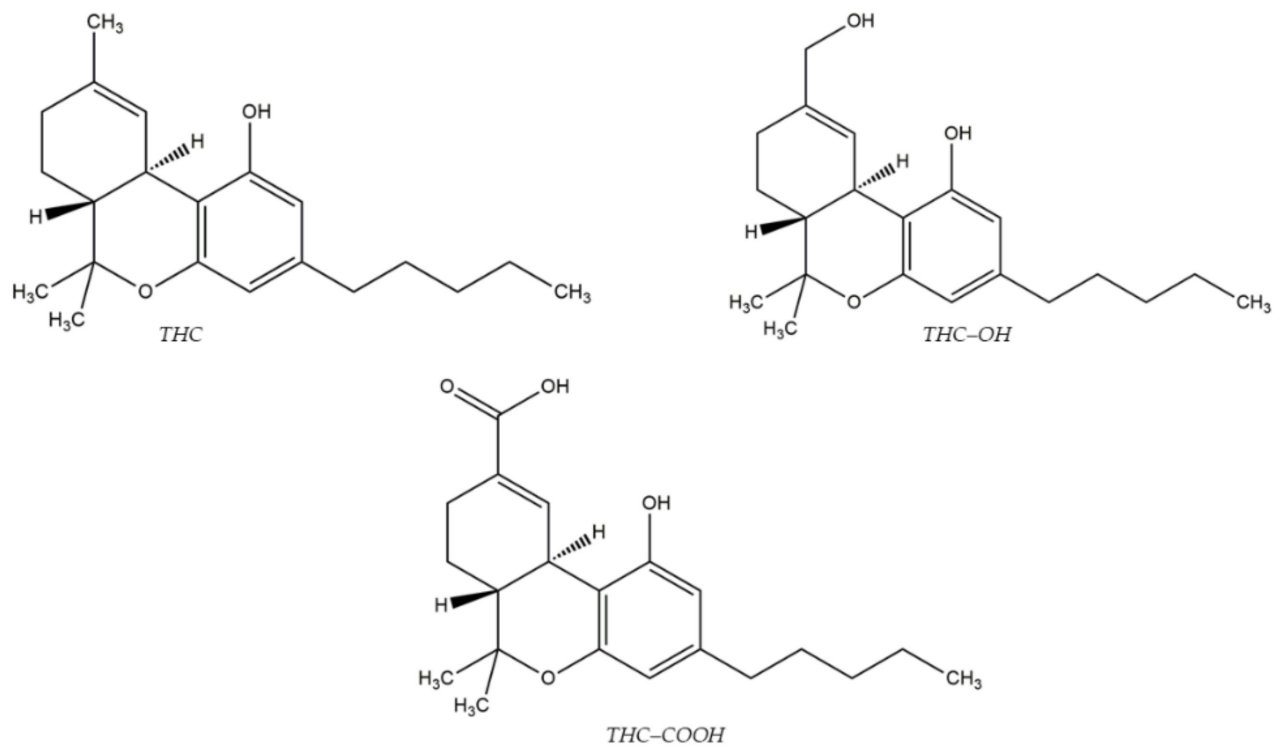

Figure 3. Chemical structures of $\Delta$ 9-tetrahydrocannabinol (THC), 11-hydroxy- $\Delta$ 9-THC (THC-OH), and 11-nor- $\triangle$ 9-THC-9-carboxylic acid (THC-COOH).

Biological post-mortem samples include urine, stomach contents, and bile, pretreated using alkaline hydrolysis, while blood and vitreous humor were pretreated with protein precipitation prior to the solid-phase extraction. SPE cartridges were preconditioned with $3 \mathrm{~mL}$ of $\mathrm{MeOH}$, followed by $3 \mathrm{~mL}$ of deionized water and $1 \mathrm{~mL}$ of $0.1 \mathrm{M}$ hydrochloric acid. Samples were then transferred to the column. Then, each column was subjected to one washing step using deionized water, followed by the addition of a $0.1 \mathrm{M}$ hydrochloric acid/acetonitrile solution (70:30, v:v). Full vacuum ( $25 \mathrm{psi})$ was then applied for $5 \mathrm{~min}$ before adding $200 \mu \mathrm{L}$ n-hexane. The target analytes were eluted with n-hexane/ethyl acetate $(50: 50, \mathrm{v}: \mathrm{v})$. The eluents were evaporated to dryness, and the samples were reconstituted with $100 \mu \mathrm{L}$ of mobile phase; $1 \mu \mathrm{L}$ was then injected into the LC-MS/MS system. The LOD ranged between $0.5-1.3 \mathrm{ng} / \mathrm{mL}$, whereas the LOQ ranged between $1-2 \mathrm{ng} / \mathrm{mL}$. Analytical recoveries for target analytes ranged from $83-97 \%$. The authors did not observe interference, and no carryover phenomena were observed. Another similar method for the identification and quantification of sixty drugs and their metabolites in post-mortem whole blood samples was described by the same authors [20]. The target analytes included illicit drugs, barbiturates, opioids, antipsychotic drugs, benzodiazepines, tricyclic antidepressants, and non-steroidal anti-inflammatory drugs (NSAIDs). The SPE extraction followed by LC-MS/MS analysis showed limits of detection (LODs) that ranged from $0.2 \mathrm{ng} / \mathrm{mL}$ to $1.0 \mathrm{ng} / \mathrm{mL}$ and limits of quantification that ranged from $1.0 \mathrm{ng} / \mathrm{mL}$ to $5.0 \mathrm{ng} / \mathrm{mL}$. Compared to the results obtained from other analytical procedures performed 
on the same target analytes with different microextraction techniques (LLE and protein precipitation extraction PPE), the lower LODs obtained in the current method highlight the better performance by using SPE for sample preparation.

Kurzweil et al. [21] have reported a method for ketamine (KET) (Figure 4) and its metabolites cis-6-hydroxynorketamine (HNK) and norketamine (NK), with the simultaneous identification of these target analytes from human blood serum by ultrafiltration and solid-phase extraction with subsequent vacuum evaporation.<smiles>[Y4]CNC1CCCC(=O)C1c1ccccc1Cl</smiles>

Figure 4. Chemical structures of ketamine.

In this case, the samples were ultrafiltrated before the extraction. For SPE, Strata-X cartridges were conditioned with $1.0 \mathrm{~mL}$ of $\mathrm{MeOH}$ followed by $1.0 \mathrm{~mL}$ of water. After loading $250 \mu \mathrm{L}$ of the ultrafiltrate, the cartridges were washed with $1.0 \mathrm{~mL}$ of water and $1.0 \mathrm{~mL}$ of $\mathrm{MeOH}$ containing 2.5\% ammonia. Elution was obtained in three steps using $\mathrm{MeOH}$ acidified with $2 \%$ formic acid. The eluate was concentrated by vacuum centrifugation and dissolved in $100 \mu \mathrm{L}$ of mobile phase before the analysis in LC-ESI-MRM. The sample preparation process was optimized to improve extraction efficacy, precision, and sensitivity. The Strata- $X$ column provided the best recovery rates in HNK analysis $(88 \pm 14 \%)$, but only poor recovery of KET (30 $\pm 3 \%)$ because of incomplete elution. The method showed good sensitivity for KET and its metabolites in human blood serum at the lowest concentration levels of $0.5 \mathrm{ng} / \mathrm{mL}, 0.6 \mathrm{ng} / \mathrm{mL}$, and $0.8 \mathrm{ng} / \mathrm{mL}$, respectively.

In 2020, Cui et al. [22] developed a rapid and efficient method for simultaneous determination of five drugs, including ephedrine, pseudoephedrine, diphenhydramine, promethazine, and terfenadine, in saliva and urine collected in cases of driving under the influence of drugs. The extraction was carried out using magnetic graphene oxide dispersive solid-phase extraction (MGO-D-SPE) combined with ion mobility spectrometry (IMS). This method was proposed for the first time and showed advantages such as good linearity covering large concentration ranges of $51.0-3040 \mathrm{ng} / \mathrm{mL}$ for five anti-hypersensitivity drugs and good accuracy with high precision ( $\mathrm{CV} \%<5.0 \%)$.

Magnetic solid-phase extraction (M-SPE) is another type of miniaturized sample preparation technique that has also been evaluated for the analysis of alternative biosamples in forensic toxicology. M-SPE is a form of dispersive solid-phase extraction in which a magnetic sorbent is directly added into the sample solution that contains the target analytes. After adsorption, the magnetic sorbent is isolated by the implementation of an external magnetic field, and the aqueous sample is discarded. Subsequently, elution is performed with the addition of an appropriate solvent, and magnetic separation takes place once again for phase separation prior to the analysis of the extract. This sample preparation approach combines the benefits of d-SPE, including the high contact area between the sorbent and the target analytes that results in high extraction efficiency, with the benefits of magnetic materials. Therefore, M-SPE is a powerful sample preparation technique that reduces the consumption of sample and organic solvents compared with the conventional SPE and LLE methods, and thus it can be considered a green technique [4]. 
In particular, magnetic graphene oxide (MGO), as a multifunctional composite with magnetics, showed excellent performance of graphene oxide (GO), like large surface area, chemical stability, and unique adsorption properties, and overcomes the insufficiency of GO that easily agglomerate.

Another new microextraction protocol based on hydrophilic interaction-dispersive solid-phase extraction (HI-d-SPE) was proposed by Giebułtowicz et al. [23] for the isolation of the potential cyanide intoxication marker, 2-aminothiazoline-4-carboxylic acid (ATCA) from postmortem blood. This method of extraction showed good results with LLOQ accuracy of $96 \%$, repeatability of $3.6 \%$, and reproducibility of $5.0 \%$. The newly proposed method has shown advantages, such as the reduction of time, laboriousness, and costs of analysis.

\subsection{Solid-Phase Microextraction}

Solid-phase microextraction is a sample preparation technique that integrates sampling, extraction, and analyte pre-concentration into a single step. SPME uses an adsorbent coated on an inert fiber; the adsorbent can be a liquid-like (polymer) or solid material. Following contact with liquid biomatrices, different kinds of analytes are transferred to the solid surface, depending on the affinity of analytes to the coating material. At equilibrium, the quantity of analyte extracted by the fiber is proportional to its concentration in the sample [11]. Once extracted, the target analytes can be desorbed by adding an appropriate organic solvent or thermally into the injection port of a gas chromatograph (GC). The main advantages of this method are simplicity, speed, volume solvent reduction, and high sensitivity, and for these reasons, this sample preparation technique is a useful tool in forensic and analytical toxicology [4].

The direct immersion SPME (DI-SPME) and the headspace SPME (HS-SPME) are two types of SPME approaches. The first extraction technique was based on the sorption of analytes on the stationary phase of fused silica, placed on the solid support with fiber directly immersed into the sample solution, while in the HS-SPME, the fiber is exposed in the vapor phase above the sample, as reported in Figure 5.

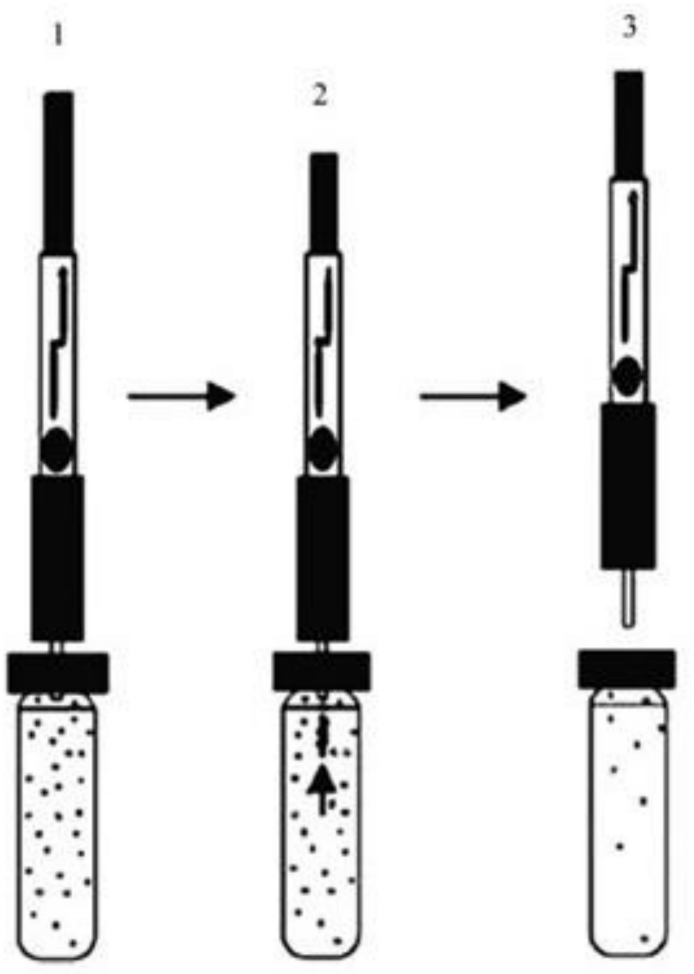

Figure 5. SPME procedure: (1) fiber in the sample; (2) extraction of the target analytes; (3) target analytes. 
Linden et al. [24] developed an efficient method by using biocompatible SPME LC Tips $\mathrm{C}_{18}$ (Sigma Aldrich, St. Louis, MO, USA), a new form of SPME fiber that is coated with HPLC-type silica. The method was validated for the simultaneous determination of cocaine (COC) and its metabolites ecgonine methyl ester (EME), benzoylecgonine (BZE), norcocaine (NCOC), and cocaethylene (CE) in human plasma after extraction with SPME LC Tips $\mathrm{C}_{18}$. A schematic representation of cocaine metabolism has been reported in Figure 6.

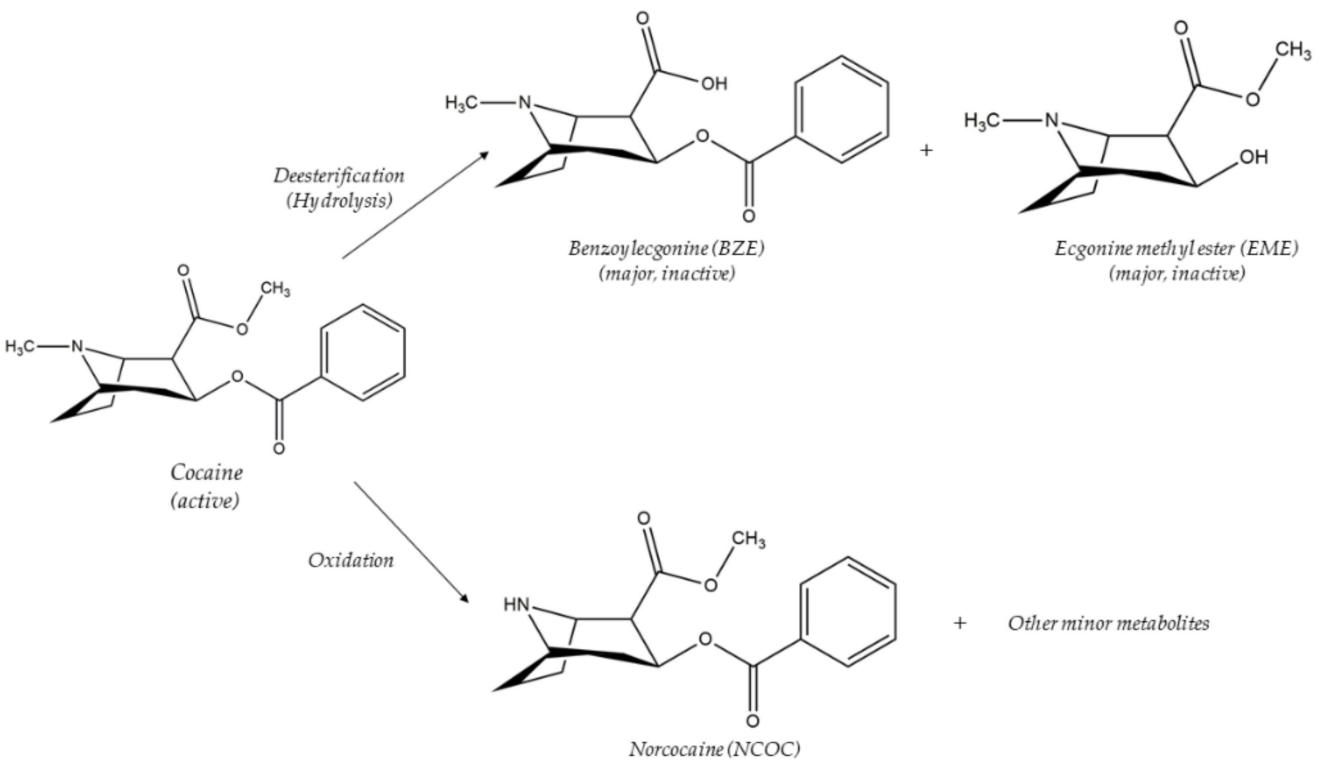

Figure 6. Cocaine metabolism.

The SPME LC Tips $\mathrm{C}_{18}$ were conditioned by $180 \mu \mathrm{L}$ of $\mathrm{MeOH}$, followed by agitation at $500 \mathrm{rpm}$ for $10 \mathrm{~min}$. A second conditioning step was performed using water at the same conditions. In another microtube, an aliquot of $50 \mu \mathrm{L}$ of plasma was added to $150 \mu \mathrm{L}$ of sodium phosphate buffer ( $\mathrm{pH}$ 8.0) containing internal standards (IS). Compounds were extracted by inserting the SPME LC Tip $\mathrm{C}_{18}$ on the resulting mixture, followed by homogenization at $500 \mathrm{rpm}$ for $30 \mathrm{~min}$. After the extraction, the desorption was performed using $180 \mu \mathrm{L}$ of $\mathrm{MeOH}$ with $0.01 \%$ formic acid; $5 \mu \mathrm{L}$ of sample was injected into the UPLC-MS/MS system for the analysis.

The LLOQ was $5 \mathrm{ng} / \mathrm{mL}$, while the limit of detection (LOD) was $0.5 \mathrm{ng} / \mathrm{mL}$ for all analytes. No carryover was detected. The main observed advantage of this procedure was the minimal amount of plasma and organic solvents used. All these characteristics made SPME a promising alternative for preparing biological samples prior to drug measurement by UPLC-MS/MS.

Majda and co-workers [8] described the first application of the newly developed DISPME/LC-TOF/MS method for the detection and quantification of 25 psychotropic drugs and their metabolites in post-mortem biological samples, including blood and bone marrow aspirate (BMA). The target analytes include antidepressants like benzodiazepines (BZDs), selective serotonin reuptake inhibitors (SSRI), serotonin and norepinephrine reuptake inhibitors (SNRI), and tricyclic antidepressants (TCA). For the extraction, SPME LC Probe $45 \mu \mathrm{m} \mathrm{C}_{18}$-Silica was chosen. Samples $(200 \mu \mathrm{L})$ were agitated at $2200 \mathrm{rpm}$ for the extraction. Adsorption was followed by purification. The fiber was wiped with a dust-free tissue then washed in the ultrapure water for $5 \mathrm{~s}$ with the vortex agitation at $5000 \mathrm{rpm}$. This phase of washing in ultrapure water and mechanical purification is important to avoid clot formation on the fiber coating due to the residues of biological materials.

Desorption was carried out with the use of $200 \mu \mathrm{L}$ of desorption solution (AcN:MeOH: $\mathrm{HCOOH}, 2: 2: 1, \mathrm{v}: \mathrm{v}: \mathrm{v})$ with the agitation of $2200 \mathrm{rpm}$ for $30 \mathrm{~min}$. After desorption, fibers were placed in the cleaning solution $\left(\mathrm{MeOH}: \mathrm{H}_{2} \mathrm{O}\right.$ :isopropanol, 2:2:1, v:v:v). The desorption solutions were evaporated, then $50 \mu \mathrm{L}$ of samples in the mobile phase were analyzed 
with the LC-TOF-MS system. For all target analytes, LOD ranged from $1.87 \mathrm{ng} / \mathrm{mL}$ to $14.27 \mathrm{ng} / \mathrm{mL}$, while LOQ from $5.60 \mathrm{ng} / \mathrm{mL}$ to $42.80 \mathrm{ng} / \mathrm{mL}$. The reported method presents many advantages: first, it is rapid and integrates extraction, concentration, and analyte desorption into a single procedure. Moreover, it is suitable for quantitative analyses, reducing sample handling, solvent use, time, and cost, allowing its application for toxicological and forensic analyses.

Nakhodchi et al. [25] developed a method using HS-SPME coupled to Ion Mobility Spectrum (IMS) for the determination of ketamine (KET) and midazolam (MDZ) in human plasma/serum samples. HS-SPME optimization was obtained with different procedural attempts in order to identify better parameters for analysis, such as sample $\mathrm{pH}$, extraction time, extraction temperature, stirring rates, and salt concentrations that could change the overall equilibrium of the analyte. In order to obtain an appropriate $\mathrm{pH}$ for extraction, the authors studied solutions with $\mathrm{pH} 4$ to 12 , and it was observed that increasing $\mathrm{pH}$ led to an increase in analytes (the best sample $\mathrm{pH}$ was 10). In addition, an increase in stirring rates facilitates the transport of analytes to the fiber, so they selected an agitation speed of $700 \mathrm{rpm}$. Furthermore, temperature is important because its increase facilitates analyte diffusion from the aqueous phase to the headspace, even if the higher temperature could have negative effects on the analysis, so they choose the better temperature for extraction, in the range of 35 to $85{ }^{\circ} \mathrm{C}$. Based on their results, a temperature of $65{ }^{\circ} \mathrm{C}$ for ketamine and $75^{\circ} \mathrm{C}$ for midazolam were chosen. Another important parameter is the adsorption time. After testing in different experimental conditions, the obtained results showed that the extracted share increases within 15 and $25 \mathrm{~min}$, respectively, for KET and MDZ, while no significant change was found for longer extraction times. Then, 15 and 25 min were selected. This method showed good satisfactory results for the simultaneous and separate detection of each of these drugs compared with other methods already published for separate quantification of ketamine and midazolam mainly based on SPE or LLE. In this procedure, it was possible to integrate sampling, extraction, and pre-enrichment in a single step, minimizing the possibility of errors.

Song et al. [26] developed a procedure based on the use of acid oxidized multiwalled carbon nanotubes (MWCNTs-COOH) as a coating material for the headspace SPME (HSSPME) by a simple physical adhesion approach. Then they validate a method with the combination of the MWCNTs-COOH-coated fiber-based HS-SPME and gas chromatographymass spectrometry (GC-MS) for the forensic determination of amphetamine (AMP) and methamphetamine (MAMP) in human urine samples (Figure 7).

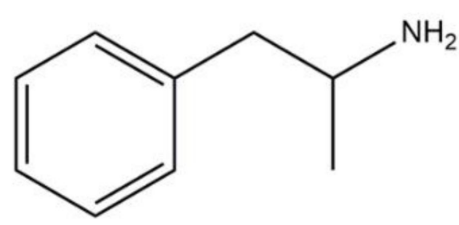

Amphetamine

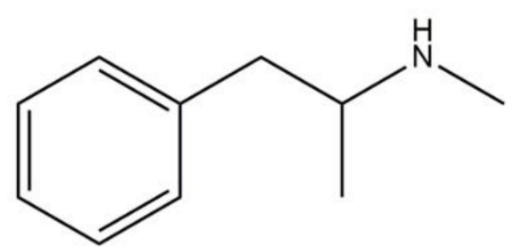

Methamphetamine

Figure 7. Chemical structures of amphetamine and methamphetamine.

Carbon nanotubes (CNTs) are cylinders of one or more layers of graphene that contain thousands of carbon atoms in an electronically aromatic delocalized system; its benefits were a strong binding affinity for hydrophobic molecules, a high surface area, mechanical strength, physical and chemical stability. Briefly, MWCNTs-COOH was obtained by the acid oxidation of pristine multi-walled carbon nanotubes (MWCNTs). The MWCNT-COOH was then immobilized on a stainless-steel wire with diluted silicone glue to obtain an MWCNTsCOOH-coated SPME fiber. As mentioned above, the extraction efficiency of SPME is influenced by the extraction conditions; for this, the HS-SPME conditions have been optimized (extraction temperature, extraction time, $\mathrm{pH}$ value, salt effect, stirring speed, temperature, and desorption time) for the extraction of amphetamine (AMP), methamphetamine (MAMP), 3,4-methylenedioxyamphetamine (MDA), 3,4-methylenedioxymethamphetamine 
(MDMA), 3,4-methylenedioxymethamphetamine (MDEA), phentermine (PTM), and 4phenylbutylamine (4-PBA, IS). The best extraction conditions were: temperature set at $80{ }^{\circ} \mathrm{C}$, extraction time of $20 \mathrm{~min}, \mathrm{pH} \mathrm{10,} \mathrm{NaCl}$ concentration of $10 \%$ (w:v), stirring speed of $900 \mathrm{rpm}$, and desorption process at $250^{\circ} \mathrm{C}$ for $5 \mathrm{~min}$. The overall characteristics demonstrate that this method can be applied in the forensic field.

\subsection{Microextraction by Packed Sorbent (MEPS)}

The microextraction by packed sorbent procedures (MEPS) is a miniaturized SPE technique with very interesting potential benefits, such as slow solvent consumption, small sample volume $(10-250 \mu \mathrm{L})$, and direct injection without further treatment. In this technique, about $1-2 \mathrm{mg}$ of sorbent (such as $\mathrm{C}_{18}, \mathrm{C}_{8}$ ) is packed in the barrel of a gas-tight syringe positioned between the needle and the barrel as a cartridge. When the sample passed through the solid bed, the analytes were adsorbed into the sorbent [11]. An illustration of the MEPS syringe is reported in Figure 8.

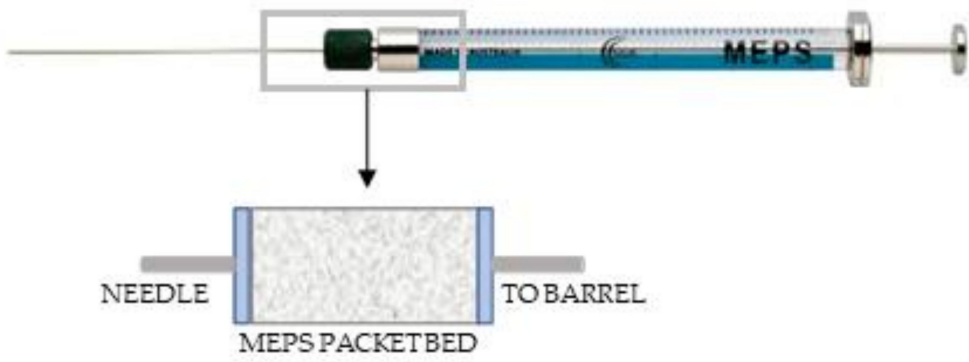

Figure 8. MEPS device.

Fernandez et al. [27] validated a simple method based on digitally programmed microextraction by packed sorbent $\left(\mathrm{eVol}^{\circledR}\right.$-MEPS, SGE, Bethel, CT, USA) coupled to ultraperformance liquid chromatography (UPLC) for the quantitative determination of three synthetic cathinones and seven conventional drugs of abuse with their metabolites. This extraction method (MEPS) coupled with the UPLC-PDA system was described for the first time for the simultaneous identification and quantification of several drugs of abuse, including three synthetic cathinones in human plasma: morphine, methylone ( $\beta \mathrm{k}-\mathrm{MDMA}$, 3,4-methylenedioxy-N-methylcathinone), 6-acetylmorphine (6-AM), mephedrone, benzoylecgonine (BEG), cocaine, 3,4-methylenedioxypyrovalerone (MDPV), cocaethylene, 2-ethylidene-1,5-dimethyl-3,3-diphenylpyrrolidine (EDDP), and methadone. Limit of detection (LOD) ranged from $0.005 \mathrm{~g} / \mathrm{mL}$ for mephedrone to $0.025 \mathrm{~g} / \mathrm{mL}$ for morphine, methylone, 6-AM, and methadone. Limit of quantification (LOQ) varied from $0.01 \mathrm{~g} / \mathrm{mL}$ for mephedrone to $0.05 \mathrm{~g} / \mathrm{mL}$ for morphine, methylone, 6-AM, and methadone. The MEPS-UPLC-PDA advantages include simplicity and speed of extraction with minimal preparation requirement.

Prata and colleagues [28] have reported a novel analytical method for the simultaneous determination of morphine, codeine, and 6-monoacetylmorphine in postmortem blood samples by gas chromatography-tandem mass spectrometry (GC-MS/MS), using microextraction by packed sorbent (MEPS) for sample preparation. One of the main limits of this technique could be the necessity of prior dilution to reduce viscosity, to prevent coagulation or blockage in the MEPS cartridge, and to achieve low backpressure. Despite this limit, the MEPS technique was better than SPE and SPME in terms of sample volumes, extraction time, analytes recovery, and sensitivity. Moreover, the sorbent can be reused several times.

Armenta et al. [29] validated a simple procedure based on microextraction by packed sorbent (MEPS) for the extraction of dichloropane in oral fluids followed by ion mobility spectrometry (IMS) analysis. Dichloropane ((-)-2 $\beta$-carbomethoxy-3 $\beta$-(3,4-dichlorophenyl) tropane, also called RTI-111 or O-401) is a compound belonging to phenyltropanes, a family 
of chemical compounds structurally related to cocaine. This target analyte was extracted from saliva samples using $\mathrm{C}_{8}$ MEPS (SGE, Bethel, CT, USA): the extraction was performed by loading $100 \mu \mathrm{L}$ of sample solution 4 times $(4 \times 100 \mu \mathrm{L})$ using a $200 \mu \mathrm{L}$ glass GC insert. Then, the sorbent was washed with $4 \times 100 \mu \mathrm{L}$ deionized water and dried by passing $3 \times 100 \mu \mathrm{L}$ air using the eVol XR digitally controlled positive displacement dispensing system. Finally, dichloropane was eluted with 2-propanol for 10 cycles $(10 \times 50 \mu \mathrm{L})$, with the final volume of $50 \mu \mathrm{L}$ ready for the IMS analysis. This MEPS-IMS procedure showed a limit of detection of $30 \mu \mathrm{g} / \mathrm{L}$, proving relative recoveries between 85 and $110 \%$.

Vincenti et al. [30] proposed an analytical method for the simultaneous determination of 25 analytes, including fentanyl, several derivates, and metabolites in human oral fluid. Sample pretreatment was carried out by MEPS followed by LC-HRMS/MS, obtaining good identification and quantification of all the analytes in less than $10 \mathrm{~min}$. The MEPS sorbent used was a $\mathrm{C}_{18}$ silica-based material with a high affinity for target analytes. As far as sample loading is concerned, the best results were achieved from the 90/10 aqueous/organic solvent ratio. LOD values ranged from $0.05 \mathrm{ng} / \mathrm{mL}$ to $0.50 \mathrm{ng} / \mathrm{mL}$, while LOQ values ranged between 0.10 and $1.0 \mathrm{ng} / \mathrm{mL}$. Overall, the technique has shown good advantages, such as short extraction times, reduced sample, and solvent consumption, and can be automated. Additionally, the method provided easy sample preparation and good sensitivity, so it could be a useful tool in forensic toxicology.

Vejar-Vivar et al. [31] have reported a method that involves sample preparation and clean-up by MEPS and its direct coupling to the electrospray ionization source of a quadrupole time-of-flight mass spectrometer (ESI-QqTOF-HRMS) for the simultaneous determination of benzodiazepines (BZDs) and tricyclic antidepressants (TCAs) in postmortem blood samples. The online MEPS-MS method consisted of coupling the MEPS syringe with the ESI-QqTOF using an infusion pump. Among the selected MEPS sorbent, the authors choose the $C_{8}$ sorbent, which gives the best results for the most analytes $(p>0.05)$. The limit of quantification (LOQ) for all compounds was equal to or below $50 \mathrm{ng} / \mathrm{mL}$. Thanks to the direct combination of the extraction phase and instrumentation, the times of analysis and the probability of error were significantly reduced. Furthermore, the use of a small volume of blood and organic solvents makes the method suitable for toxicological screening and for the quantitative analysis of most of the investigated drugs.

Costa et al. [32] validated a method for simultaneous identification of nine synthetic opioids (fentanyl, sufentanil, alfentanil, acrylfentanyl, thiofentanyl, valerylfentanyl, furanylfentanyl, acetyl fentanyl, and carfentanil) and two metabolites (norfentanyl and acetyl norfentanyl) in urine samples by microextraction with packed sorbent (MEPS) and liquid chromatography-tandem mass spectrometry (LC-MS/MS). Before MEPS extraction, urine samples were diluted with $600 \mu \mathrm{L}$ ultra-pure water to avoid cartridge clogging. The total $800 \mu \mathrm{L}$ of sample was loaded onto the MEPS BIN cartridge with different draw/eject cycles of $50 \mu \mathrm{L}$. Before the first sample extraction, the BIN cartridge was conditioned two times with $50 \mu \mathrm{L}$ of $\mathrm{MeOH}$ and two times with $50 \mu \mathrm{L}$ ultra-pure water. The sample fortified with the IS was loaded and released $(3.57 \mu \mathrm{L} / \mathrm{s})$ eight times. Next, the sample was washed twice with $50 \mu \mathrm{L}$ ultra-pure water and isopropyl alcohol (95:5, v:v). Finally, analytes were eluted with $50 \mu \mathrm{L}$ of AcN. During method development, the urine dilution with ultra-pure water led to better efficiency. BIN cartridges were reused until efficiency was lost or clogging occurred (approximately 150 times). The limit of detection (LOD) was $0.1 \mathrm{ng} / \mathrm{mL}$, whereas the limit of quantification (LOQ) was $1 \mathrm{ng} / \mathrm{mL}$. Compared to other methods, this procedure achieved high sensitivity using less sample volume. The offered advantages of this method were the small volumes of sample $(200 \mu \mathrm{L})$ and solvents required, the possible automation, and a lower cost compared to conventional SPE. Moreover, the extraction procedure requires only $10 \mathrm{~min}$ per sample and can be easily applied to routine laboratories.

\subsection{Liquid-Liquid Extraction (LLE)}

Liquid-liquid extraction is one of the first sample preparation techniques used for biological sample analysis. This technique is based on the transfer of analytes from the 
aqueous sample to a water-immiscible solvent based on the octanol-water partition coefficient $\left(\log \mathrm{K}_{\mathrm{o} / \mathrm{w}}\right)$. Traditional LLE has some disadvantages, such as emulsion formation, the use of large sample volumes, and the toxic nature of the organic solvents; moreover, this procedure usually involves several steps that are difficult to automate [11]. To overcome all these drawbacks, the LLE method was optimized with other techniques that are also in forensic toxicology-one of these is liquid-phase microextraction (LPME).

Degreef et al. [33] performed a liquid-liquid extraction (LLE) for the identification and quantification of 40 antidepressants in $200 \mu \mathrm{L}$ of human plasma for forensic purposes. The authors chose this reconstitution step extraction technique for sample preparation due to its simplicity and efficiency. Then, the samples were injected onto an LC system coupled with a triple quadrupole. With LLE, interference was removed from the sample with minimal loss of sensitivity. The calibration curves ranged from sub-therapeutic to toxic concentrations. With simple sample cleaning, a relatively short chromatographic run, and a wide calibration range, this method can be applied in therapeutic drug monitoring and forensic research.

Furthermore, Zawadzki and co-workers [34] have presented a rapid, sensitive, and precise method validated for the quantification of sufentanil in human plasma for forensic purposes using ultra-performance liquid chromatography (UHPLC) coupled with QqQMS/MS system. Liquid-liquid extraction (LLE) was performed using ethyl acetate $(2 \mathrm{~mL})$ for $10 \mathrm{~min}$. Samples were centrifuged at $1400 \times g$, and the organic phase was evaporated to dryness under a nitrogen stream (at $40{ }^{\circ} \mathrm{C}$ ). The extract was dissolved in $50 \mu \mathrm{L}$ of $\mathrm{MeOH}$ before the analysis. The lower limit of quantification (LLOQ) in human plasma was $0.010 \mu \mathrm{g} / \mathrm{L}$; LOD was considered at $0.0050 \mu \mathrm{g} / \mathrm{L}$. LLE showed advantages, such as shorter analysis time, a small volume sample required for extraction, and a very simple and fast sample preparation method; these benefits made the method suitable for clinical toxicology and forensic analysis.

\subsection{Liquid-Phase Microextraction (LPME)}

Liquid-phase microextraction (LPME) is a sample preparation technique in which the target analytes are extracted from an aqueous solution with a small volume of extraction solvent. There are three main types of LPME based on how the extraction solvent contacts the sample to extract the target analytes: a single drop microextraction (SDME), hollow fiber liquid-phase microextraction (HF-LPME), and dispersive liquid-liquid microextraction (DLLME) [4]. The most used techniques for forensic purposes are HF-LPME and DLLME, following the procedure reported in Figure 9.

Hollow fiber liquid-phase microextraction (HF-LPME) typically employs disposable propylene fibers that contain the extraction solvent. The hollow fiber is immersed in the aqueous sample solution that contains the target analytes for the extraction. There are two main types of HF-LPME: two-phase HF-LPME and three-phase HF-LPME. In the first approach, the hollow fibers contain the organic solvent (acceptor phase), and extraction takes place via passive diffusion of the analytes from the aqueous sample (donor phase) to the acceptor phase. This method is used for the extraction of analytes with low polarity, and the technique is compatible with GC since the extraction and preconcentration of the analytes are performed by an organic solvent.

In the second case, after the extraction of the analytes to the organic solvent that is immobilized in the pores of the fiber, the analytes are further extracted into a new aqueous phase in the lumen of the fiber. This method is used for ionizable compound extraction (acids and bases). The main benefits of HF-LPME are its low cost, its high efficiency regarding sample clean up, as well as the provision of high enrichment factors [4]. With HF-LPME, it is possible to extract target analytes from aqueous samples, across a supported liquid membrane (SLM) and into an acceptor solution, so it requires specialized equipment. 


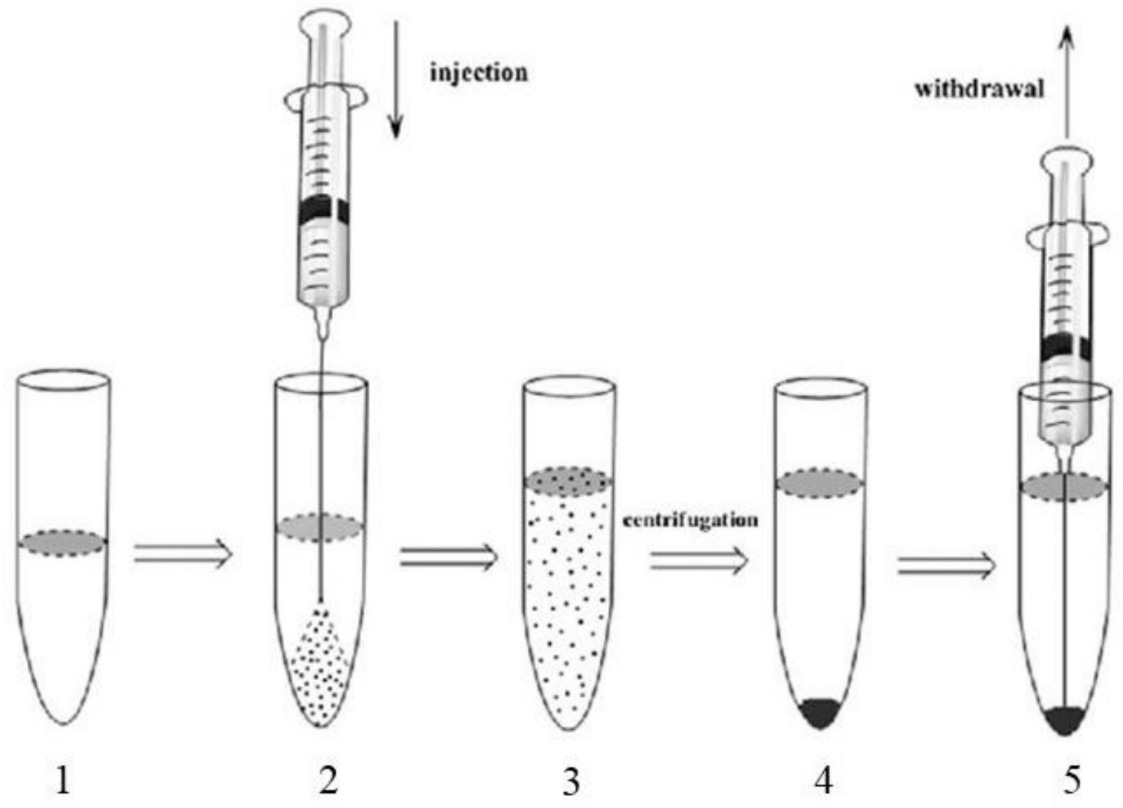

Figure 9. DLLME procedure: (1) sample with analytes; (2) dispersive solvent injection; (3) dispersion; (4) sedimentation; (5) removal of the sediment.

In the field of forensic toxicology, Bombana et al. [35] validated a gas chromatography-mass spectrometry (GC-MS) method combined with HF-LPME for the determination of amphetamine (AMP), methamphetamine (MET), fenproporex (FEN), 3,4-methylenedioxymethamphetamine (MDMA), 3,4-methylene-dioxyamphetamine (MDA), and 3,4-methylenedioxyethylamphetamine (MDEA) in whole blood. The samples were prepared using a three-phase HF-LPME to trap the target molecules inside the fiber lumen; therefore, an aqueous solution with a $\mathrm{pH}$ different from that of the analytes was used. An acid solution based on hydrochloric acid was used as the acceptor phase, while the biological matrix diluted in sodium hydroxide ( $\mathrm{pH}$ between 12 and 13) was the donor phase. Sodium hydroxide $(2.5 \mathrm{~mL} \mathrm{NaOH} 1 \mathrm{M}$, $\mathrm{pH}=12$ ) was added to $500 \mu \mathrm{L}$ of whole blood to constitute the donor phase. Hollow-fiber pores were filled with dihexyl ether by submersion for $10 \mathrm{~s}$ into the organic solvent. The lumen of the hollow fibers was filled with $50 \mu \mathrm{L}$ of hydrochloric acid $(\mathrm{HCl} 1 \mathrm{M}, \mathrm{pH}=3)$ as the acceptor phase. Then, the solution was stirred for $30 \mathrm{~min}$ at $1500 \mathrm{rpm}$. The limits of detection ranged from 1 to $3 \mathrm{ng} / \mathrm{mL}$, while the limits of quantification ranged from 2 to $5 \mathrm{ng} / \mathrm{mL}$. The proposed procedure shows advantages, such as low consumption of organic solvent, easy neutralization of the solution used as acceptor and donor phases, and small volume of sample $(500 \mu \mathrm{L}$, less than other methods using humor vitreous $(2 \mathrm{~mL})$, urine $(1 \mathrm{~mL})$, or blood $(1 \mathrm{~mL}))$. Due to the overall benefits that emerged from this work, the proposed HF-LPME method presented a cleaner and less expensive alternative to the classical extraction methods.

Dispersive liquid-liquid microextraction is another form of LPME that is based on a ternary solvent system involving an appropriate mixture of water-immiscible organic solvent as the extraction solvent and water-miscible organic solvent as the disperser solvent, which is injected rapidly into an aqueous sample solution with the use of a syringe. This process could also be used as ionic liquids (ILs) or deep eutectic solvents (DES) in order to improve the extraction efficiency. The resulting cloudy solution was centrifuged, and the fine droplets that sedimented into a few microliters were removed manually by a syringe and analyzed by various analytical techniques $[4,11]$. The benefits of this technique are unique, such as a high pre-concentration factor for the target analytes, low cost, simplicity, and the possibility of combined use with almost every analytical measurement technique.

Vincenti et al. [36] developed a new analytical procedure for hair testing; in particular, they validated a multiclass method for the simultaneous extraction, identification, and 
quantification of sixty drugs of abuse from different chemical classes, with a high-resolution mass spectrometer with Orbitrap technology. Different experimental conditions were tested in terms of chromatographic separation and ion signal, and of extraction and cleanup, combining pressurized liquid extraction (PLE) with the peculiarities of DLLME. The sample was first treated with a decontamination step by washing the samples with different solvents (water/methanol and water/ethanol, followed by washing with isopropanol if necessary) to remove any external interference caused by drugs and cosmetic treatments. Subsequently, the sample is pretreated with extraction and subsequent cleaning. The PLE method was used for the decontamination and extraction of the analytes from the internal core of the hair, while the cleaning was performed by liquid-liquid dispersive microextraction (DLLME). PLE is a technique that can be applied to hair analysis with a significant reduction in extraction times. In other studies, this technique was combined with the SPE method for extraction and cleaning, while in the validated method, PLE was used to achieve both decontamination and hair extraction, and they also improved cleaning using DLLME. LOD values ranged from $0.1 \mathrm{pg} / \mathrm{mg}$ to $5 \mathrm{pg} / \mathrm{mg}$, while LOQs were between $0.2 \mathrm{pg} / \mathrm{mg}$ and $50 \mathrm{pg} / \mathrm{mg}$. These values are absolutely acceptable for all the analytes, especially for a method that involves the determination of many substances belonging to different chemical classes. This multiclass method has shown many benefits, first the application of PLE for hair decontamination and also because this extraction procedure provides reduction of analytical time $(14 \mathrm{~min})$ compared to the traditional method that requires up to $18-24 \mathrm{~h}$. Moreover, it reduces sample volume with a single analysis, rather than one for each class or group of substances; it also reduces the amount of organic solvent volume and provides quantitative results to concurrently confirm the assumption of one or more illicit substances.

Mercieca et al. [37] developed a high-throughput and rapid method for the determination of more than 25 stimulants of different classes such as amphetamine-type stimulants, synthetic cathinones, phenethylamines, ketamine and analogs, benzofurans, and tryptamines from blood and urine samples using ultra-rapid DLLME and simultaneous derivatization for sample pretreatment, followed by GC-MS. The extraction of analytes was performed by dispersive liquid-liquid microextraction (DLLME). The optimized conditions for DLLME were $100 \mu \mathrm{L}$ of a binary solvent system of chloroform as extractant and $250 \mu \mathrm{L}$ of methanol as disperser solvent for urine, while $200 \mu \mathrm{L}$ of chloroform and $500 \mu \mathrm{L}$ of methanol were used for blood samples. To obtain the formation of the cloudy solution, $350 \mu \mathrm{L}$ of a 1:2.5 mixture of chloroform:methanol was added to urine samples and to deproteinized blood samples. The samples were then centrifuged, and the obtained solution (about $50 \mu \mathrm{L}$ ) was transferred into a vial, and $1.0 \mu \mathrm{L}$ was injected into the GC-MS system. The proposed validation of the method showed good and satisfactory results for simultaneous derivatization and extraction of analytes from biological samples. No interferences from endogenous matrix compounds were observed from both samples. The advantages that emerged from this method made the procedure useful, efficient, and really applicable for forensic purposes.

The field of forensic toxicology also includes laboratory investigations for doping. In this context, Temerdashev and co-workers [38] developed an ultra-high performance liquid chromatography-tandem mass-spectrometry (UHPLC-MS/MS) method for the quantification of two commonly abused arylpropionamide-derived selective androgen receptor modulators (SARMs), namely S-4 (GTx-007, andarine), and S-22 (GTx-024, MK2866, ostarine, enobosarm). The analysis was performed on a urine sample prepared with dispersive liquid-liquid microextraction (DLLME) using methanol and chloroform as dispersive and extracting solvents. The limit of detection (LOD) was $0.05 \mathrm{ng} / \mathrm{mL}$ for both drugs, while the limit of quantification was $0.5 \mathrm{ng} / \mathrm{mL}$. The benefits of the presented procedure were simplicity and high sensitivity; moreover, the method was fast (time of sample preparation and UHPLC-MS/MS quantification is < $20 \mathrm{~min}$ ) with the use of a small volume of toxic solvents. 
De Boeck et al. [39] developed a method with IL-DLLME coupled to LC-MS/MS for the quantification of 18 antidepressants in whole blood. The target analytes were agomelatine, amitriptyline, bupropion, clomipramine, dosulepin, doxepin, duloxetine, escitalopram, fluoxetine, imipramine, maprotiline, mianserin, mirtazapine, nortriptyline, paroxetine, reboxetine, trazodone, and venlafaxine. This method was based on a ternary solvent system. The organic extraction solvent and the dispersing solvent were injected into the aqueous sample at the same time, creating a fine dispersion and, thus, a large contact surface that promotes the transfer of the analyte to the extraction solvent. One milliliter of whole blood was added with $1.0 \mathrm{~mL}$ of aqueous buffer (pH 3.0) and $60 \mu \mathrm{L}$ of IL extraction solvent (1-butyl-3-methylimidazolium hexafluorophosphate $\left(\mathrm{BMIm}^{\mathrm{PF}} \mathrm{F}_{6}\right)$ ). Prior to adding the extraction solvent, $1.0 \mathrm{~mL}$ of $\mathrm{pH} 8.0$ aqueous buffer was used to deprotonate the basic analytes. The sample was first mixed for $5 \mathrm{~min}$ and then centrifuged; the lower IL phase was collected and diluted at 1:10 in MeOH before the LC-MS/MS analysis. LOQs were set at the lowest calibrator concentration, and LOD values ranged between 1 and $2 \mathrm{ng} / \mathrm{mL}$.

Recovery values were within the range of $53.11-132.98 \%$; matrix effect values were within the range of $61.92-123.24 \%$. Overall, the method showed many benefits, such as selectivity, accuracy, and precision with desired sensitivity. Only for fluvoxamine did the method not show the desired accuracy and precision, so this analyte was included in the semi-quantitative method. Compared with other sample preparation techniques for antidepressants (LLE or SPE), IL-DLLME showed good results, minimal consumption of extraction solvent $(60 \mu \mathrm{L})$, and an optimized processing time with minimal time of analysis (less than $30 \mathrm{~min}$ ) and cost. These advantages make IL-DLLME a potential procedure for forensic analysis in complex whole blood matrices. The described microextraction procedure was also applied in postmortem samples. The same authors have investigated its application coupled with liquid chromatography-tandem mass spectrometry (LC-MS/MS) for the analysis of benzodiazepines (BZD) in post-mortem blood (peripheral blood from a femoral vein) of 11 forensic cases [40]. In this work, the same procedure previously reported was applied and compared to a validated SPE-LC-MS/MS method. Of the 11 analyzed post-mortem samples, 51 BZDs, and BZD-like hypnotics were observed using the SPE-LCMS/MS method, whereas the IL-DLLME-LC-MS/MS method was able to detect 48 of 51 BZDs. Both methods gave comparable qualitative and quantitative results. Lormetazepam concentration was below the limit of detection and was not detected using IL-DLLME-LCMS/MS. However, it should be noted that the observed concentration was sub-therapeutic and of limited forensic relevance. Furthermore, tetrazepam was not detected, as it was not included in the IL-DLLME method. These overall results highlight the complexity of the analysis performed on postmortem samples due to the factors that could influence quantification, such as chemical and biological degradation processes.

\subsection{Other Techniques}

Vardal et al. [41] developed an alternative extractive procedure for sample preparation. They validated a parallel artificial liquid membrane extraction (PALME) for sample preparation of DBZD (diclazepam, clonazolam, and etizolam), benzodiazepines (BZD), and Z-hypnotics in whole blood prior to UHPLC-MS/MS analysis. Parallel artificial liquid membrane extraction (PALME) is a microextraction technique in which analytes from the sample are extracted using an aqueous donor solution (sodium hydroxide is often used), with a passive diffusion mechanism across a liquid membrane organic supported (SLM) in an aqueous acceptor solution (extract). The chosen acceptor solution was dimethyl sulfoxide (DMSO) and $200 \mathrm{mM}$ formic acid (HCOOH 75:25, v:v). The extraction is facilitated by a $\mathrm{pH}$ gradient and can be compared to LLE with back-extraction. The solvent for the SLM was a combination of 2-undecanone and dihexyl ether $(1: 1, \mathrm{w}: \mathrm{w})$ with $1 \%$ trioctylamine (w:w). The equipment used for PALME consisted of a 96-well donor plate of polypropylene with $0.50 \mathrm{~mL}$ wells, and a 96-well acceptor plate with polyvinylidene fluoride (PVDF), serving as support for the SLM. The pore size of the PVDF material was $0.45 \mu \mathrm{m}$, and the internal diameter was $6.0 \mathrm{~mm}$. The donor wells were filled with $250 \mu \mathrm{L}$ of donor solution 
composed of $100 \mu \mathrm{L}$ of whole blood, $130 \mu \mathrm{L} 50 \mathrm{mM}$ of phosphate buffer (pH 7.5), and $20 \mu \mathrm{L}$ of internal standard. The SLM was prepared by pipetting $4.0 \mu \mathrm{L}$ of the mixture 2-undecanone and dihexyl ether $(1: 1, w: w)$ with $1 \%$ trioctylamine $(w: w)$ onto the PVDF material, with the acceptor plate turned upside down. After about $5 \mathrm{~s}$, the acceptor plate was turned back, and the acceptor wells were filled with $150 \mu \mathrm{L}$ of acceptor solution. LOD values ranged from 0.10 to $5.0 \mathrm{ng} / \mathrm{mL}$. The LLOQs were equal to the lowest calibration standard (ranged from 2.0 to $100 \mathrm{ng} / \mathrm{mL}$ ). This procedure, compared to other methods for the analysis of BZD and Z-hypnotics in whole blood, showed a reduction of the sample preparation steps with less time and used a limited amount of sample material $(0.1 \mathrm{~mL})$ and reagents. Moreover, this microextraction technique could preserve specificity, accuracy, and sensitivity with high reproducibility.

Recently, Ask et al. [42] analyzed human plasma for forensic purposes with the LCMS/MS method combined with a 96-well LPME method for the simultaneous extraction of amitriptyline, nortriptyline, quetiapine, venlafaxine, o-desmethylvenlafaxine, and fluoxetine. This new approach showed important benefits, such as simple workflow with a rapid time of extraction (about $60 \mathrm{~min}$ ) and low consumption of organic solvent (less than $0.4 \mathrm{~mL}$ ), according to the Green Analytical Chemistry principles. PALME was performed using a 96-well polypropylene donor plate with $0.5 \mathrm{~mL}$ wells. The acceptor plate was a 96-well MultiScreen-IP filter plate. The membrane material was polyvinylidene fluoride (PVDF) with a pore size of $0.45 \mu \mathrm{m}$. The donor solution (125 $\mu \mathrm{L}$ of plasma, $10 \mu \mathrm{L}$ of IS, and $115 \mu \mathrm{L}$ of sodium hydroxide $40 \mathrm{mM}$ ) was pipetted into the donor wells. In the acceptor plate, the SLM was prepared with $4 \mu \mathrm{L}$ of $1 \%$ (v:v) trioctylamine in dodecyl acetate, then the acceptor solution ( $50 \mu \mathrm{L} 20 \mathrm{mM}$ formic acid) was added into the acceptor wells. The donor and acceptor plate were placed on a Vibramax 100 platform shaker for extraction at $900 \mathrm{rpm}$ for $60 \mathrm{~min}$. After the extraction, the acceptor solutions were analyzed into the LC-MS system. The mean recoveries (independent of analyte concentration) were between $48-85 \%$, with corresponding RSD values between $2-7 \%$.

A new method widely applied in forensic medicine is QuEChERS as Quick, Easy, Cheap, Effective, Rugged, and Safe. In this method, the supernatant is easily separated after centrifugation and ready to be injected into analytical devices, such as gas chromatographymass spectrometry (GC-MS), liquid chromatography-mass spectrometry (LC-MS), and high-performance liquid chromatography (HPLC), which can be used as a "green", fast, and effective way to detect drugs in clinical and forensic investigations and death cases. Many authors proposed this technique as a simple method for qualitative and quantitative analysis of drugs and medicine, thanks to its sensitivity and renewability. Moreover, it did not require specific equipment and required less time; for these reasons, it has a great potential for analyzing clinical and legal samples.

For example, Orfanidis et al. [43] developed an ultra-high performance liquid chromatography-tandem mass spectrometry (UHPLC-MS/MS) method for the identification and quantification of 84 drugs and pharmaceuticals in post-mortem blood (collected after 14-20 h postmortem). The target compounds comprise pharmaceutical drugs (antipsychotics, antidepressants, etc.) and some of the most important groups of drugs of abuse, such as opiates, cocaine, cannabinoids, amphetamines, benzodiazepines, and new psychoactive substances (NPS). Sample pretreatment was performed with a single-step QuEChERS extraction protocol. This method was modified due to the small sample volume, and different protocols were tested: acetonitrile or ethyl acetate was used for the extraction step with potassium carbonate (with or without $\mathrm{NaCl}$ ). Both single extraction and a two-step procedure with the use of Primary Secondary Amine (PSA) adsorbent for removing interferences were applied. The best results were obtained with the addition of a mixture of $20 \mathrm{mg} \mathrm{MgSO}_{4}, 5 \mathrm{mg} \mathrm{K} \mathrm{CO}_{3}$, and $5 \mathrm{mg} \mathrm{NaCl}$ together with $600 \mu \mathrm{L}$ of cold AcN in $200 \mu \mathrm{L}$ of sample. After centrifugation, the sample was collected for direct injection. The QuEChERS method was found to be selective and sensitive and has provided satisfactory recoveries and sample clean-up. The limit of quantitation (LOQ) ranging from $0.03 \mathrm{ng} / \mathrm{mL}$ (for $25 \mathrm{C}-\mathrm{NB}_{2} \mathrm{OMe}$ and $25 \mathrm{I}-\mathrm{NB}_{2} \mathrm{OMe}$ ) to $27.2 \mathrm{ng} / \mathrm{mL}$ (for valproic acid) and the 
detection limit (LOD) ranged between $0.01 \mathrm{ng} / \mathrm{mL}$ (for $25 \mathrm{C}-\mathrm{NB}_{2} \mathrm{OMe}$ and 25I-NB $\mathrm{NB}_{2} \mathrm{OMe}$ ) and $9.07 \mathrm{ng} / \mathrm{mL}$ (for valproic acid). The method has been applied for the analysis of small volumes of post-mortem blood and has proven to be an invaluable tool for clinical and forensic applications providing less accurate results in half an hour. The table below reports the main parameters obtained from the validation of other published methods (Table 1).

\subsection{Fabric Phase Sorptive Extraction (FPSE) as an Innovative Procedure in the Biological Field}

The same microextraction techniques, together with others that are not currently applied to postmortem samples, have wide applications in the biological field. In this context, the analysis of the sample does not assume a forensic value but represents an important phase in the diagnostic and therapeutic management of various pathologies. Most biological samples are incompatible with analytical instruments, as other substances in the sample can interfere during the measurement. Furthermore, analytes are typically present at low concentration levels, not being detectable by the analytical instrument. Therefore, sample pre-treatment and clean-up procedures are often necessary.

To date, the number of different microextraction techniques and their applications to various analytical fields are continuously increasing, usually to improve compatibility with modern analytical tools, to avoid the use of hazardous chemicals, and to allow sampling from a very small biological sample volume. For example, a recent microextraction technique introduced in 2014 is Fabric Phase Sorptive Extraction (FPSE). FPSE is an innovative microextraction technique that uses a flexible fabric surface of different materials (cotton, polyester, and fiberglass) as a substrate platform for creating hybrid organic/inorganic sol-gel absorbent coatings. The FPSE device can be introduced directly into the vial containing the sample, eliminating any previous pretreatment steps such as filtration, protein precipitation, defatting, and centrifugation, as reported in Figure 10. The FPSE is then removed from the sample matrix, and the target analytes are desorbed/eluted using a small volume of the organic solvent prior to the chromatographic analysis. Furthermore, unlike other techniques, the substrate in this case not only has the function of hosting the sorbent phase but also plays a key role in determining the overall selectivity of the FPSE device through hydrophobic/hydrophilic interactions. FPSE has innovatively integrated the extraction principles typical of SPME and SPE in a single technological platform. First, it resembles SPME for direct immersion in which the extraction membrane remains immersed in the aqueous solution containing the analyte of interest during the extraction (equilibrium extraction). On the other hand, the permeable substrate in FPSE and the spongy and porous mesh of the sol-gel sorbent coating establish a quasi-flow system that mimics an SPE disc (exhaustive extraction). Fabric phase sorptive extraction is the only microextraction technique that offers a wide range of sorbent chemistries, including polar, medium polar, nonpolar, cation exchanger, anion exchanger, mixed-mode, zwitterionic, as well as zwitterionic mixed-mode sorbents.

Until now, this technique has been evaluated for the extraction of numerous target analytes from various bioanalytical matrices prior to their determination by instrumental analytical techniques. All developed methodologies reported in the literature since 2014 are briefly described below, showing the wide range of applicability of this technique in terms of biological matrices and analyte multiplicity. 
Table 1. Microextraction techniques used in the forensic and biological field.

\begin{tabular}{|c|c|c|c|c|c|c|}
\hline Target Analytes & Matrix & $\begin{array}{l}\text { Extraction } \\
\text { Technique }\end{array}$ & $\begin{array}{c}\text { Analysis } \\
\text { Technique }\end{array}$ & LOQ & LOD & Ref. \\
\hline 7-Aminoflunitrazepam & \multirow{26}{*}{ Whole blood } & \multirow{26}{*}{ IL-DLLME } & \multirow{26}{*}{ LC-ESI-MS/MS } & $2 \mathrm{ng} / \mathrm{mL}$ & $0.09 \mathrm{ng} / \mathrm{mL}$ & \multirow{26}{*}{ [44] } \\
\hline Alprazolam & & & & $2 \mathrm{ng} / \mathrm{mL}$ & $0.28 \mathrm{ng} / \mathrm{mL}$ & \\
\hline Bromazepam & & & & $10 \mathrm{ng} / \mathrm{mL}$ & $0.67 \mathrm{ng} / \mathrm{mL}$ & \\
\hline Brotizolam & & & & $2 \mathrm{ng} / \mathrm{mL}$ & $1.41 \mathrm{ng} / \mathrm{mL}$ & \\
\hline Chlordiazepoxide & & & & $50 \mathrm{ng} / \mathrm{mL}$ & $4.74 \mathrm{ng} / \mathrm{mL}$ & \\
\hline Clobazam & & & & $50 \mathrm{ng} / \mathrm{mL}$ & $3.49 \mathrm{ng} / \mathrm{mL}$ & \\
\hline Clonazepam & & & & $2 \mathrm{ng} / \mathrm{mL}$ & $0.25 \mathrm{ng} / \mathrm{mL}$ & \\
\hline Clorazepate & & & & $10 \mathrm{ng} / \mathrm{mL}$ & $0.69 \mathrm{ng} / \mathrm{mL}$ & \\
\hline Clotiazepam & & & & $50 \mathrm{ng} / \mathrm{mL}$ & $0.54 \mathrm{ng} / \mathrm{mL}$ & \\
\hline Cloxazolam & & & & $10 \mathrm{ng} / \mathrm{mL}$ & $3.63 \mathrm{ng} / \mathrm{mL}$ & \\
\hline Diazepam & & & & $50 \mathrm{ng} / \mathrm{mL}$ & $2.16 \mathrm{ng} / \mathrm{mL}$ & \\
\hline Estazolam & & & & $10 \mathrm{ng} / \mathrm{mL}$ & $0.40 \mathrm{ng} / \mathrm{mL}$ & \\
\hline Ethyl loflazepate & & & & $10 \mathrm{ng} / \mathrm{mL}$ & $0.94 \mathrm{ng} / \mathrm{mL}$ & \\
\hline Etizolam & & & & $2 \mathrm{ng} / \mathrm{mL}$ & $0.26 \mathrm{ng} / \mathrm{mL}$ & \\
\hline Flunitrazepam & & & & $2 \mathrm{ng} / \mathrm{mL}$ & $0.18 \mathrm{ng} / \mathrm{mL}$ & \\
\hline Flurazepam & & & & $2 \mathrm{ng} / \mathrm{mL}$ & $0.03 \mathrm{ng} / \mathrm{mL}$ & \\
\hline Loprazolam & & & & $2 \mathrm{ng} / \mathrm{mL}$ & $0.003 \mathrm{ng} / \mathrm{mL}$ & \\
\hline Midazolam & & & & $10 \mathrm{ng} / \mathrm{mL}$ & $0.50 \mathrm{ng} / \mathrm{mL}$ & \\
\hline Nitrazepam & & & & $10 \mathrm{ng} / \mathrm{mL}$ & $0.61 \mathrm{ng} / \mathrm{mL}$ & \\
\hline Nordiazepam & & & & $10 \mathrm{ng} / \mathrm{mL}$ & $0.69 \mathrm{ng} / \mathrm{mL}$ & \\
\hline Oxazepam & & & & $50 \mathrm{ng} / \mathrm{mL}$ & $1.78 \mathrm{ng} / \mathrm{mL}$ & \\
\hline Prazepam & & & & $50 \mathrm{ng} / \mathrm{mL}$ & $1,83 \mathrm{ng} / \mathrm{mL}$ & \\
\hline Temazepam & & & & $10 \mathrm{ng} / \mathrm{mL}$ & $0.46 \mathrm{ng} / \mathrm{mL}$ & \\
\hline Triazolam & & & & $2 \mathrm{ng} / \mathrm{mL}$ & $0.28 \mathrm{ng} / \mathrm{mL}$ & \\
\hline Zolpidem & & & & $10 \mathrm{ng} / \mathrm{mL}$ & $0.43 \mathrm{ng} / \mathrm{mL}$ & \\
\hline Zopiclone & & & & $2 \mathrm{ng} / \mathrm{mL}$ & $0.33 \mathrm{ng} / \mathrm{mL}$ & \\
\hline Phenethylamine (2C) & \multirow{4}{*}{ Human plasma } & \multirow{4}{*}{ LLE } & \multirow{4}{*}{ LC-HRMS } & \multirow{4}{*}{$0.25 \mathrm{ng} / \mathrm{mL}$} & \multirow{4}{*}{$0.1 \mathrm{ng} / \mathrm{mL}$} & \multirow{4}{*}[45]{} \\
\hline $\begin{array}{c}\text { N-2-methoxybenzyl } \\
\text { phenethylamine (NBOMes) }\end{array}$ & & & & & & \\
\hline Lysergic acid diethylamide (LSD) & & & & & & \\
\hline Fentanyl & & & & & & \\
\hline New Psychoactive Substances (NPS) & Oral fluid & MEPS & UHPLC-MS/MS & $0.015-2.600 \mathrm{ng} / \mathrm{mL}$ & $0.005-0.850 \mathrm{ng} / \mathrm{mL}$ & [46] \\
\hline
\end{tabular}


Table 1. Cont.

\begin{tabular}{|c|c|c|c|c|c|c|}
\hline Target Analytes & Matrix & $\begin{array}{l}\text { Extraction } \\
\text { Technique }\end{array}$ & $\begin{array}{l}\text { Analysis } \\
\text { Technique }\end{array}$ & LOQ & LOD & Ref. \\
\hline 44 opioid-related and analgesic compounds & $\begin{array}{l}\text { Postmortem whole } \\
\text { blood, urine, liver, brain }\end{array}$ & SPE & UHPLC-Ion Trap-MS & not reported & $0.1-5 \mathrm{ng} / \mathrm{mL}$ & [47] \\
\hline $\begin{array}{c}\text { Methadone } \\
\text { Amphetamine (AMP) }\end{array}$ & Postmortem urine & QuEChERS & GC-MS & $97 \mathrm{ng} / \mathrm{mL}$ & $29.1 \mathrm{ng} / \mathrm{mL}$ & [10] \\
\hline $\begin{array}{l}\text { Methamphetamine (MAMP) } \\
\text { 3,4-Methylenedioxyamphetamine (MDA) }\end{array}$ & \multicolumn{5}{|c|}{ 3,4-Methylenedioxyamphetamine (MDA) } & \\
\hline $\begin{array}{l}\text { 3,4-Methylenedioxymethamphetamine } \\
\text { (MDMA) }\end{array}$ & Human whole blood & UA-DLLME & GC-MS & $40 \mathrm{ng} / \mathrm{mL}$ & $10 \mathrm{ng} / \mathrm{mL}$ & [48] \\
\hline \multicolumn{7}{|l|}{ Meperidine (MEP) } \\
\hline \multicolumn{7}{|l|}{ Methadone (METD) } \\
\hline \multicolumn{7}{|l|}{ Ketamine (KET) } \\
\hline $\begin{array}{c}\text { Psychoactive Substances (PAS) } \\
\text { (16 antidepressants, } 7 \text { antipsychotics and } \\
3 \text { metabolites, norfluoxetine, norsertraline) } \\
\text { 3,4-Methylenedioxymethamphetamine } \\
\text { (MDMA) }\end{array}$ & Postmortem blood & QuEChERS & UFLC-MS/MS & not reported & $1 \mathrm{ng} / \mathrm{mL}$ & [49] \\
\hline $\begin{array}{c}\text { 3,4-Methylenedioxyamphetamine (MDA) } \\
\text { 3,4-Methylenedioxyethylamphetamine } \\
\text { (MDEA) }\end{array}$ & Postmortem blood & LLME & UFLC-MS/MS & $0.1-1 \mathrm{ng} / \mathrm{mL}$ & $0.1-1 \mathrm{ng} / \mathrm{mL}$ & [50] \\
\hline \multicolumn{7}{|l|}{$\begin{array}{l}\text { N-methoxybenzyl- } \\
\text { methoxyphenylethylamine } \\
\text { (NBOMes) }\end{array}$} \\
\hline Amitriptyline & & & & $0.001 \mu \mathrm{g} / \mathrm{mL}$ & $0.0003 \mu \mathrm{g} / \mathrm{mL}$ & \\
\hline Citalopram & & & & $0.001 \mu \mathrm{g} / \mathrm{mL}$ & $0.0003 \mu \mathrm{g} / \mathrm{mL}$ & \\
\hline Chlorpromazine & & & & $0.001 \mu \mathrm{g} / \mathrm{mL}$ & $0.0003 \mu \mathrm{g} / \mathrm{mL}$ & \\
\hline Clozapine & & & & $0.01 \mu \mathrm{g} / \mathrm{mL}$ & $0.003 \mu \mathrm{g} / \mathrm{mL}$ & \\
\hline Fluoxetine & & & & $0.01 \mu \mathrm{g} / \mathrm{mL}$ & $0.003 \mu \mathrm{g} / \mathrm{mL}$ & \\
\hline Haloperidol & Postmortem serum, & QuEChERS & UHPLC-MS/MS & $0.001 \mu \mathrm{g} / \mathrm{mL}$ & $0.0003 \mu \mathrm{g} / \mathrm{mL}$ & [51] \\
\hline Mirtazapine & whole blood & & & $0.01 \mu \mathrm{g} / \mathrm{mL}$ & $0.003 \mu \mathrm{g} / \mathrm{mL}$ & \\
\hline Nortriptyline & & & & $0.001 \mu \mathrm{g} / \mathrm{mL}$ & $0.0003 \mu \mathrm{g} / \mathrm{mL}$ & \\
\hline Olanzapine & & & & $0.05 \mu \mathrm{g} / \mathrm{mL}$ & $0.017 \mu \mathrm{g} / \mathrm{mL}$ & \\
\hline Paroxetine & & & & $0.001 \mu \mathrm{g} / \mathrm{mL}$ & $0.0003 \mu \mathrm{g} / \mathrm{mL}$ & \\
\hline Quetiapine & & & & $0.01 \mu \mathrm{g} / \mathrm{mL}$ & $0.003 \mu \mathrm{g} / \mathrm{mL}$ & \\
\hline Risperidone & & & & $0.005 \mu \mathrm{g} / \mathrm{mL}$ & $0.0017 \mu \mathrm{g} / \mathrm{mL}$ & \\
\hline
\end{tabular}


Table 1. Cont.

\begin{tabular}{|c|c|c|c|c|c|c|}
\hline Target Analytes & Matrix & $\begin{array}{l}\text { Extraction } \\
\text { Technique }\end{array}$ & $\begin{array}{l}\text { Analysis } \\
\text { Technique }\end{array}$ & LOQ & LOD & Ref. \\
\hline $\begin{array}{l}\text { Sertraline } \\
\text { Venlafaxine } \\
\text { Zolpidem }\end{array}$ & $\begin{array}{l}\text { Postmortem serum, } \\
\text { whole blood }\end{array}$ & QuEChERS & UHPLC-MS/MS & $\begin{array}{c}0.005 \mu \mathrm{g} / \mathrm{mL} \\
0.01 \mu \mathrm{g} / \mathrm{mL} \\
0.001 \mu \mathrm{g} / \mathrm{mL}\end{array}$ & $\begin{array}{c}0.0017 \mu \mathrm{g} / \mathrm{mL} \\
0.003 \mu \mathrm{g} / \mathrm{mL} \\
0.0003 \mu \mathrm{g} / \mathrm{mL}\end{array}$ & [51] \\
\hline $\begin{array}{c}\text { Psychoactive drugs and some metabolites } \\
\text { Barbiturates }\end{array}$ & Whole blood & QuEchERS & UPLC-MS/MS & - & $0.36-0.78 \mathrm{ng} / \mathrm{mL}$ & [52] \\
\hline Benzodiazepines & & & & $1.1-5.0 \mathrm{ng} / \mathrm{mL}$ & $0.21-2.3 \mathrm{ng} / \mathrm{mL}$ & \\
\hline $\begin{array}{c}\text { Tri/tetracyclic antidepressants } \\
\text { Drugs of abuse } \\
\text { Phenethylamines }\end{array}$ & Human whole blood & $\mathrm{dSPE}$ & GC-MS/MS & $\begin{array}{l}1.0-10 \mathrm{ng} / \mathrm{mL} \\
1.0-5.0 \mathrm{ng} / \mathrm{mL} \\
1.0-5.0 \mathrm{ng} / \mathrm{mL}\end{array}$ & $\begin{array}{c}0.32-0.50 \mathrm{ng} / \mathrm{mL} \\
0.20-1.6 \mathrm{ng} / \mathrm{mL} \\
1.4-4.9 \mathrm{ng} / \mathrm{mL}\end{array}$ & [53] \\
\hline Pesticides & & & & $\begin{array}{l}10-16 \mathrm{ng} / \mathrm{mL} \\
1.0-5.0 \mathrm{ng} / \mathrm{mL}\end{array}$ & $0.09-1.4 \mathrm{ng} / \mathrm{mL}$ & \\
\hline $\begin{array}{c}\text { Antidepressants } \\
\text { 2-aminothiazoline-4-carboxylic acid } \\
\text { (ATCA) } \\
\text { Amphetamine (AMP) }\end{array}$ & $\begin{array}{l}\text { Postmortem blood } \\
\text { Synthetic urine } \\
\text { Bovine blood }\end{array}$ & 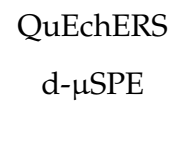 & $\begin{array}{c}\text { LC-MS/MS } \\
\text { GC-MS }\end{array}$ & $\begin{array}{l}10 \mathrm{ng} / \mathrm{mL} \\
10 \mathrm{ng} / \mathrm{mL} \\
60 \mathrm{ng} / \mathrm{mL}\end{array}$ & $\begin{array}{l}10 \mathrm{ng} / \mathrm{mL} \\
5 \mathrm{ng} / \mathrm{mL} \\
10 \mathrm{ng} / \mathrm{mL}\end{array}$ & $\begin{array}{l}{[54]} \\
{[55]}\end{array}$ \\
\hline $\begin{array}{c}\text { Methamphetamine (MA) } \\
\text { 3,4-Methylenedioxyamphetamine (MDA) } \\
\text { N-ethyl-3,4- } \\
\text { methylenedioxyamphetamine } \\
\text { (MDEA) } \\
\text { N-methyl-3,4- } \\
\text { methylenedioxyamphetamine } \\
\text { (MDMA) }\end{array}$ & $\begin{array}{l}\text { Oral fluid, urine, serum, } \\
\text { sweat, breast milk, hair, } \\
\text { and fingernails }\end{array}$ & SUPRAS & LC-MS/MS & $5-100 \mathrm{ng} / \mathrm{mL}$ & not reported & [56] \\
\hline $\begin{array}{c}\text { Illicit drugs } \\
\text { Synthetic cannabinoids } \\
\text { JWH-200 } \\
\text { AM-694 }\end{array}$ & Urine & DLLME & HPLC-MS & $\begin{array}{l}0.01-0.37 \mu \mathrm{g} / \mathrm{L} \\
0.004 \mathrm{ng} / \mathrm{mL} \\
0.013 \mathrm{ng} / \mathrm{mL} \\
0.009 \mathrm{ng} / \mathrm{mL}\end{array}$ & $\begin{array}{l}0.006-0.072 \mu \mathrm{g} / \mathrm{L} \\
0.002 \mathrm{ng} / \mathrm{mL} \\
0.008 \mathrm{ng} / \mathrm{mL} \\
0.006 \mathrm{ng} / \mathrm{mL}\end{array}$ & [57] \\
\hline $\begin{array}{l}\text { JWH-250 } \\
\text { JWH-073 }\end{array}$ & Oral fluid & DLLME & HPLC-MS/MS & $\begin{array}{l}0.035 \mathrm{ng} / \mathrm{mL} \\
0.016 \mathrm{ng} / \mathrm{mL}\end{array}$ & $\begin{array}{l}0.021 \mathrm{ng} / \mathrm{mL} \\
0.010 \mathrm{ng} / \mathrm{mL}\end{array}$ & [58] \\
\hline $\begin{array}{l}\text { JWH-018 } \\
\text { JWH-019 }\end{array}$ & & & & $0.030 \mathrm{ng} / \mathrm{mL}$ & $0.018 \mathrm{ng} / \mathrm{mL}$ & \\
\hline $\begin{array}{l}\text { Ketoprofen } \\
\text { Diclofenac }\end{array}$ & Human urine & LLME & HPLC-UV & not reported & $\begin{array}{l}15 \mu \mathrm{g} / \mathrm{L} \\
44 \mu \mathrm{g} / \mathrm{L}\end{array}$ & [59] \\
\hline
\end{tabular}


Table 1. Cont.

\begin{tabular}{|c|c|c|c|c|c|c|}
\hline Target Analytes & Matrix & $\begin{array}{l}\text { Extraction } \\
\text { Technique }\end{array}$ & $\begin{array}{c}\text { Analysis } \\
\text { Technique }\end{array}$ & LOQ & LOD & Ref. \\
\hline Nortriptyline & $\begin{array}{l}\text { Human breast } \\
\text { milk, urine }\end{array}$ & DLPME & IMS & $5.0 \mu \mathrm{g} / \mathrm{L}$ & $1.9 \mu \mathrm{g} / \mathrm{L}$ & {$[60]$} \\
\hline $\begin{array}{l}\text { Sertraline (SER) } \\
\text { Imipramine (IMI) }\end{array}$ & \multirow{2}{*}{ Human plasma } & \multirow{2}{*}{ HS-SPME } & \multirow{2}{*}{ IMS } & $0.26 \mu \mathrm{g} / \mathrm{mL}$ & $\begin{array}{l}0.08 \mu \mathrm{g} / \mathrm{mL} \\
0.12 \mu \mathrm{g} / \mathrm{mL}\end{array}$ & \multirow{2}{*}[61]{} \\
\hline Alprazolam (ALP) & & & & $\begin{array}{l}0.39 \mu \mathrm{g} / \mathrm{mL} \\
0.89 \mu \mathrm{g} / \mathrm{mL}\end{array}$ & $0.27 \mu \mathrm{g} / \mathrm{mL}$ & \\
\hline Chlorpromazine & \multirow{5}{*}{ Human plasma } & \multirow{5}{*}{ SPE } & \multirow{5}{*}{ LC-MS/MS } & $13.17 \mathrm{ng} / \mathrm{mL}$ & $3.95 \mathrm{ng} / \mathrm{mL}$ & \multirow{5}{*}{62} \\
\hline Levomepromazine & & & & $4.99 \mathrm{ng} / \mathrm{mL}$ & $1.50 \mathrm{ng} / \mathrm{mL}$ & \\
\hline Olanzapine & & & & $2.89 \mathrm{ng} / \mathrm{mL}$ & $0.87 \mathrm{ng} / \mathrm{mL}$ & \\
\hline Risperidone & & & & $4.59 \mathrm{ng} / \mathrm{mL}$ & $1.378 \mathrm{ng} / \mathrm{mL}$ & \\
\hline Sulpiride & & & & $7.04 \mathrm{ng} / \mathrm{mL}$ & $2.11 \mathrm{ng} / \mathrm{mL}$ & \\
\hline Antipsychotic & Plasma & LLE & LC-MS/MS & not reported & not reported & {$[63]$} \\
\hline $\begin{array}{l}\text { Anastrozole } \\
\text { Letrozole } \\
\text { Exemestane }\end{array}$ & $\begin{array}{l}\text { Human whole blood, } \\
\text { plasma, urine }\end{array}$ & FPSE & HPLC-PDA & $0.05 \mu \mathrm{g} / \mathrm{mL}$ & $0.02 \mu \mathrm{g} / \mathrm{mL}$ & [64] \\
\hline Ketamine (KET) & \multirow{3}{*}{ Human plasma } & \multirow{3}{*}{ PPE } & \multirow{3}{*}{ HPLC-MS/MS } & $20 \mathrm{ng} / \mathrm{mL}$ & $10 \mathrm{ng} / \mathrm{mL}$ & \multirow{3}{*}{65} \\
\hline Nor-ketamine (NK) & & & & $470 \mathrm{ng} / \mathrm{mL}$ & $410 \mathrm{ng} / \mathrm{mL}$ & \\
\hline $\begin{array}{c}\text { Midazolam 1-hydroxy midazolam } \\
\text { (1HMDZ) }\end{array}$ & & & & $150 \mathrm{ng} / \mathrm{mL}$ & $100 \mathrm{ng} / \mathrm{mL}$ & \\
\hline $\begin{array}{l}\text { Atenolol } \\
\text { Metoprolol } \\
\text { Tacrolimus }\end{array}$ & Human urine samples & tCap- $\mu \mathrm{Ex}$ & $\mathrm{CE}$ & $\begin{array}{l}3.27 \mathrm{ng} / \mathrm{mL} \\
2.10 \mathrm{ng} / \mathrm{mL} \\
0.8 \mathrm{ng} / \mathrm{mL}\end{array}$ & $\begin{array}{l}1.13 \mathrm{ng} / \mathrm{mL} \\
0.75 \mathrm{ng} / \mathrm{mL} \\
0.3 \mathrm{ng} / \mathrm{mL}\end{array}$ & [66] \\
\hline $\begin{array}{l}\text { Sirolimus } \\
\text { Everolimus }\end{array}$ & \multirow[t]{2}{*}{ Human whole blood } & \multirow[t]{2}{*}{ SPME } & \multirow[t]{2}{*}{ MOI-MS/MS } & $\begin{array}{l}0.7 \mathrm{ng} / \mathrm{mL} \\
1 \mathrm{ng} / \mathrm{mL}\end{array}$ & $\begin{array}{l}0.2 \mathrm{ng} / \mathrm{mL} \\
0.3 \mathrm{ng} / \mathrm{mL}\end{array}$ & \multirow[t]{2}{*}{67} \\
\hline Cyclosporine A & & & & $0.8 \mathrm{ng} / \mathrm{mL}$ & $0.3 \mathrm{ng} / \mathrm{mL}$ & \\
\hline Ketoconazole & \multirow{5}{*}{ Human plasma, Urine } & \multirow{5}{*}{ FPSE } & \multirow{5}{*}{ HPLC-PDA } & \multirow{5}{*}{$0.1 \mu \mathrm{g} / \mathrm{mL}$} & \multirow{5}{*}{$0.03 \mu \mathrm{g} / \mathrm{mL}$} & \multirow{5}{*}{ [68] } \\
\hline Terconazole & & & & & & \\
\hline $\begin{array}{l}\text { Voriconazole } \\
\text { Bifonazole }\end{array}$ & & & & & & \\
\hline Clotrimazole & & & & & & \\
\hline Tioconazole & & & & & & \\
\hline
\end{tabular}


Table 1. Cont.

\begin{tabular}{|c|c|c|c|c|c|c|}
\hline Target Analytes & Matrix & $\begin{array}{l}\text { Extraction } \\
\text { Technique }\end{array}$ & $\begin{array}{l}\text { Analysis } \\
\text { Technique }\end{array}$ & LOQ & LOD & Ref. \\
\hline $\begin{array}{c}\text { Econazole } \\
\text { Butoconazole } \\
\text { Miconazole } \\
\text { Posaconazole } \\
\text { Ravuconazol } \\
\text { Itraconazole }\end{array}$ & Human plasma, Urine & FPSE & HPLC-PDA & $0.1 \mu \mathrm{g} / \mathrm{mL}$ & $0.03 \mu \mathrm{g} / \mathrm{mL}$ & [68] \\
\hline $\begin{array}{c}\text { Ketamine (KET) } \\
\text { Nor ketamine (n-KET) } \\
\text { Dehydronorketamine (DHNK) } \\
\text { Hydroxynorketamine (HNK) } \\
\text { Hydroxyketamine (HK) }\end{array}$ & $\begin{array}{l}\text { Human serum, urine, } \\
\text { feces }\end{array}$ & LLE & LC-MS/MS & $0.1 \mathrm{ng} / \mathrm{mL}$ & not reported & [69] \\
\hline $\begin{array}{l}\text { Atenolol } \\
\text { Propranolol } \\
\text { Metoprolol }\end{array}$ & Plasma & LPME-DESs & GC-MS & $\begin{array}{l}0.645 \mathrm{ng} / \mathrm{mL} \\
0.435 \mathrm{ng} / \mathrm{mL} \\
0.692 \mathrm{ng} / \mathrm{mL}\end{array}$ & $\begin{array}{l}0.195 \mathrm{ng} / \mathrm{mL} \\
0.130 \mathrm{ng} / \mathrm{mL} \\
0.205 \mathrm{ng} / \mathrm{mL}\end{array}$ & {$[70]$} \\
\hline $\begin{array}{l}\text { Nortriptyline } \\
\text { Papaverine } \\
\text { Loperamide } \\
\text { Haloperidol }\end{array}$ & $\begin{array}{l}\text { Human urine, dried } \\
\text { blood spot }\end{array}$ & $\mu$-EME & CE-UV & not reported & $5-28 \mathrm{ng} / \mathrm{mL}$ & [71] \\
\hline
\end{tabular}




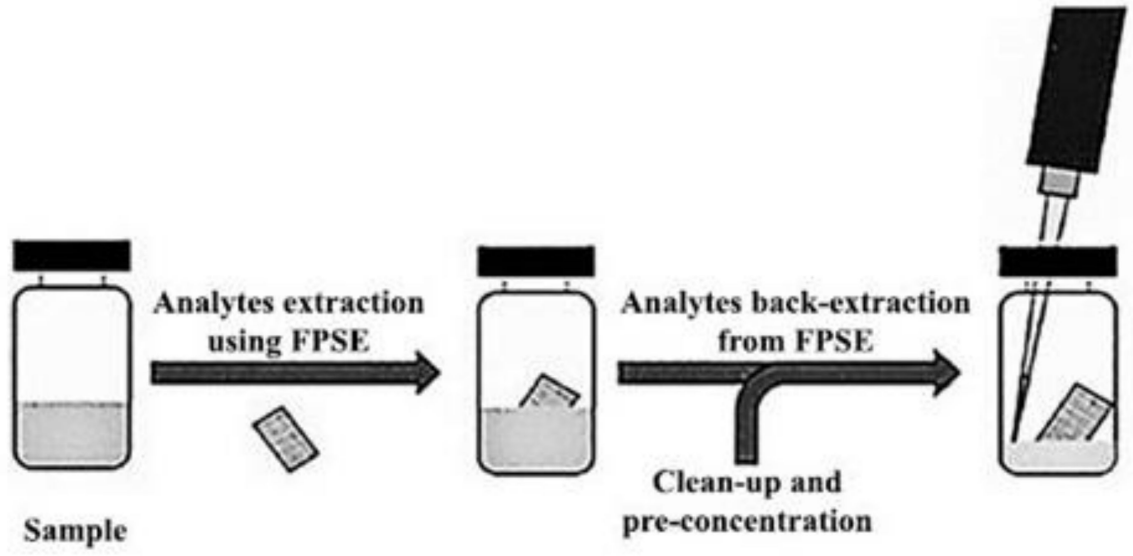

Figure 10. FPSE technique.

Kumar and co-workers [72] have reported a simple, fast, and sensitive method using fabric-phase sorptive extraction (FPSE) followed by high-performance liquid chromatography with fluorescence detection (HPLC-FLD) for the quantification of selected estrogens, e.g., $17 \alpha$-ethynylestradiol (EE2), $\beta$-estradiol (E2), and bisphenol A (BPA). Various factors affecting the performance of the FPSE technique were optimized. A cleaned sol-gel polytetrahydrofuran (sol-gel PTHF)-coated FPSE medium was inserted into a glass vial containing the target analytes $(10 \mathrm{ng} / \mathrm{mL})$, and the sample solution was stirred at $1000 \mathrm{rpm}$ for $20 \mathrm{~min}$ for the sorption of analytes into it. After extraction, the FPSE fiber was removed from the vial and soaked into $0.5 \mathrm{~mL}$ of $\mathrm{MeOH}$ for $8 \mathrm{~min}$. Finally, the eluted solvent containing the target analytes was centrifuged for $5 \mathrm{~min}$ to obtain a particulate-free solution. The centrifuged solution was injected into the HPLC system. The developed method was successfully applied for the analysis of estrogen molecules in urine samples. Furthermore, the carryover phenomenon was evaluated for FPSE media. The membrane was washed with pure methanol, and the carryover was checked by injecting the elution solvent three times. A minor residue was observed, so a thorough cleaning step was performed after each extraction process. The reduction of analysis times makes the reported method economic and ecological. The validation parameters of the method yielded good results, demonstrating that this developed method is rapid, accurate, reproducible, and sensitive for the determination of selected estrogens in urine samples.

Alonso and collaborators [73] have reported an extraction method based on sorptive fabric-phase coupled to ultra-high-performance liquid chromatography-tandem mass spectrometry (FPSE-UHPLC-MS/MS) detection for the determination of four progestogens and six androgens in environmental and biological samples. Several parameters that can affect the FPSE, such as the sample volume, ionic strength, $\mathrm{pH}$, extraction and desorption times, and the volume desorption solvent, have been evaluated. In the end, the optimum conditions were as follows: extraction for $20 \mathrm{~min}$ of the different samples at a $\mathrm{pH}$ of 5.70 and $0 \%$ of $\mathrm{NaCl}$ using sol-gel poly(tetrahydrofuran) sorbent, and desorption with $750 \mu \mathrm{L}$ of $\mathrm{MeOH}$ for $3 \mathrm{~min}$. In these conditions, the theoretical preconcentration factor was calculated as 26.6 for urine samples.

Samanidou et al. [74] have described a new sample preparation protocol using fabricphase sorptive extraction technique for the determination of benzodiazepines in blood serum by high-performance liquid chromatography. The drugs included bromazepam (BRZ), diazepam (DZP), lorazepam (LRZ), and alprazolam (APZ). Prior to the extraction, the FPSE medium was conditioned using $2 \mathrm{~mL}$ of $\mathrm{AcN}: \mathrm{MeOH}(50: 50, \mathrm{v}: \mathrm{v})$ and was subsequently rinsed in $2 \mathrm{~mL}$ Milli-Q to remove residual organic solvents. The extraction was performed using sol-gel polyethylene glycol (sol-gel PEG)-coated FPSE media by direct immersion in the sample for $20 \mathrm{~min}$. Then, the FPSE medium was inserted into $500 \mu \mathrm{L}$ AcN:MeOH (50:50, v:v) for $10 \mathrm{~min}$. The eluate can be either directly injected into the HPLC 
system or evaporated to dryness under the nitrogen stream and reconstituted using $50 \mu \mathrm{L}$ AcN:MeOH (50:50, v:v) for further preconcentration. In addition, it was observed that the FPSE media could be reused up to approximately 30 times with no carryover effect.

Locatelli et al. [68] have described a new FPSE-HPLC-PDA method for the simultaneous extraction and analysis of twelve azole antimicrobial drugs, including ketoconazole, terconazole, voriconazole, bifonazole, clotrimazole, tioconazole, econazole, butoconazole, miconazole, posaconazole, ravuconazole, and itraconazole in human plasma and urine samples. The different tested FPSE membranes were cut into circular disks with an internal diameter of $1 \mathrm{~cm}$ (surface area of $0.785 \mathrm{~cm}^{2}$ ) in order to obtain an identical surface area for all devices. After cutting, the FPSE membrane was subjected to a series of device conditioning/activation steps with AcN:MeOH (50:50, v:v) and Milli-Q water. The final optimized conditions were: (i) sample extraction using sol-gel Carbowax ${ }^{\circledR} 20 \mathrm{M}$ (Sigma Aldrich, St. Louis, MO, USA), in $500 \mu \mathrm{L}$ of plasma (or $1 \mathrm{~mL}$ of urine) for $30 \mathrm{~min}$; (ii) elution using $150 \mu \mathrm{L}$ of $\mathrm{MeOH}$ for $10 \mathrm{~min}$; (iii) centrifuge at 12,000× $\mathrm{g}$ for $10 \mathrm{~min}$; (iv) inject $20 \mu \mathrm{L}$ of the supernatant into an HPLC-PDA instrument.

Kabir and coworkers [75] have reported a new method for the simultaneous extraction and analysis of three drug residues (ciprofloxacin, sulfasalazine, and cortisone) in human whole blood, plasma, and urine samples, generally used for inflammatory bowel disease (IBD) treatment. The optimized extraction procedure was performed using sol-gel Carbowax $^{\circledR} 20 \mathrm{M}$ medium (previously activated and washed with AcN:MeOH mixture and Milli-Q water) placed in the biological matrix sample for $30 \mathrm{~min}$; elution required the use of $150 \mu \mathrm{L}$ of $\mathrm{MeOH}$ for $10 \mathrm{~min}$; a $20 \mu \mathrm{L}$ aliquot was injected into the HPLC-PDA instrument after centrifugation. The method was applied for the extraction of target analytes from whole blood, plasma, and urine samples collected from IBD patients during their normal clinical therapy protocol. The results showed that the method could be applied for drug monitoring in biological fluids, including the direct analysis of whole blood. In addition, it has been observed that the FPSE membranes can be reused up to approximately 30 times with no appreciable residual effect and no loss of efficiency.

Locatelli and coworkers [64] have reported a new sensitive and selective FPSE-HPLCPDA procedure for the analyses of aromatase inhibitors (anastrozole, letrozole, and exemestane) in whole blood, plasma, and urine samples collected from women in treatment for metastatic breast cancer. The selected FPSE membranes (sol-gel polyethylene glycolpolypropylene glycol-polyethylene glycol, PEG-PPG-PEG) were cleaned using AcN:MeOH (50:50, v:v) for $5 \mathrm{~min}$ followed by washing the membrane in $2 \mathrm{~mL}$ of Milli-Q water. Subsequently, the membranes were inserted into the sample $(500 \mu \mathrm{L}$ of plasma or $1 \mathrm{~mL}$ of urine or $1 \mathrm{~mL}$ of diluted whole blood), and the extractions were conducted for $30 \mathrm{~min}$. Subsequently, the analytes were eluted using $150 \mu \mathrm{L}$ of $\mathrm{MeOH}$ for $10 \mathrm{~min}$. In the end, the sample was centrifuged at $12,000 \times g$, and a $20 \mu \mathrm{L}$ aliquot was directly injected into the HPLC-PDA system. The data obtained from biological samples collected from women in treatment for metastatic breast cancer during their normal medical treatment practice unequivocally support the validity of the new validated method to simultaneously monitor the residues of three anticancer drugs in the considered biological fluids, including whole blood. No pretreatment step was performed prior to extraction of whole blood, which was diluted only with Milli-Q water to decrease its viscosity and consequently increase the diffusivity of the analytes within the matrix, reducing extraction times.

FPSE has also been applied for the biomonitoring of compounds potentially dangerous to human health. Some compounds that have been widely discussed in recent years include so-called endocrine disruptors (EDCs), which are products with negative effects on the endocrine system due to their interaction with the production, release, transport, metabolism, or elimination of hormones. In view of this, regulatory agencies, such as the Food and Drug Administration (FDA) and the European Union (EU), have imposed maximum limits for these compounds in cosmetic, food, and pharmaceutical products. Therefore, the evaluation of these compounds in different biological fluids becomes fundamental for the biomonitoring of human exposure to EDCs. In light of this, 
Locatelli et al. [76] have applied an FPSE-HPLC-PDA method for the simultaneous extraction and analysis of six benzophenone derivative UV filters in human whole blood, plasma, and urine samples. Tartaglia et al. [77] described the FPSE approach for the biomonitoring of the most commonly used parabens in biological fluids (whole blood, plasma, and urine). Alampanos et al. [78] reported an innovative magnet-integrated fabric-phase sorptive extraction (MI-FPSE) device as a new analytical methodology for the determination of selected very common endocrine-disrupting chemicals in human urine. Parla and co-workers [79] have described an FPSE-HPLC-UV method for the quantitation of seven parabens in human plasma samples. In all cases, the FPSE procedure applied to different biological matrices has shown various advantages, eliminating the pretreatment steps, such as centrifugation, protein precipitation, and post-treatment steps, such as evaporation of the solvent and reconstitution of the sample from the sample preparation workflow; in addition, whole blood analysis is performed directly, avoiding the use of plasma or serum.

Lioupi and coworkers [80] have described an innovative FPSE-HPLC-PDA method for the simultaneous extraction and analysis of five common antidepressants (venlafaxine, paroxetine, fluoxetine, amitriptyline, clomipramine) in human urine samples. The extraction was carried out using sol-gel graphene as an FPSE device, initially activated in $2 \mathrm{~mL}$ of acetonitrile: methanol (50:50, v:v) for $2 \mathrm{~min}$ and subsequently rinsed in $2 \mathrm{~mL}$ of Milli-Q water to dispose of the remaining organic solvents. The device was then introduced into the aqueous sample for $20 \mathrm{~min}$ for extraction of the target analytes. Subsequently, the FPSE device was placed in a clean analyte elution vial with $500 \mu \mathrm{L}$ of AcN:MeOH (50:50, v:v) for $10 \mathrm{~min}$. The eluate was injected directly into the HPLC system. The reported method has provided high absolute recovery (\%R) values for all five antidepressant drugs.

Alampanos et al. [81] have described an innovative FPSE procedure for the determination of four penicillin antibiotics residues (benzylpenicillin, cloxacillin, dicloxacillin, and oxacillin) in human blood serum. The sol-gel poly tetrahydrofuran (sol-gel PTHF)-coated FPSE membrane showed optimum extraction sensitivity for the selected penicillin antibiotics, which were analyzed using an RP-HPLC method. After the activation process, the sol-gel PTHF was inserted into the sample matrix containing a clean Teflon-coated magnetic stir bar (a magnetic stirrer was set at the highest level to ensure sufficient analyte diffusion) for $25 \mathrm{~min}$. The elution was performed, inserting the FPSE medium, submersed into $500 \mu \mathrm{L}$ of $\mathrm{ACN}: \mathrm{CH}_{3} \mathrm{COONH}_{4}(90: 10, \mathrm{v}: \mathrm{v})$. The final eluate can be directly injected into the HPLC system for chromatographic analysis. The steps of protein precipitation and solvent evaporation, followed by sample reconstitution, were eliminated, making the developed method less error-prone and time-consuming than conventional sample preparation techniques. The amount of solvents used has been significantly reduced. Furthermore, it was observed that the FPSE membrane is reusable for at least 35 times without any statistically significant loss of extraction efficiency.

Tartaglia and colleagues [82] have described a rapid FPSE-HPLC-PDA method that allows simultaneous clean-up and determination of six non-steroidal anti-inflammatory drugs (NSAIDs) in saliva samples. Particularly, furprofen, indoprofen, ketoprofen, fenbufen, flurbiprofen, and ibuprofen were considered in this study. An important innovation has been included in this study, where FPSE devices were tested as Dried Saliva Spot (DSS) for the first time. The FPSE device was used as an adsorbent to sample the biological matrix (in this case saliva) and, after drying, as a storage device, just like the dried blood spot (DBS) procedure. The DSS membrane was cut into round pieces (diameter $=1 \mathrm{~cm}$ ), and the optimized volume of $100 \mu \mathrm{L}$ of saliva was placed on the membrane and dried overnight. Once dried, the membrane was inserted in $150 \mu \mathrm{L}$ of $\mathrm{MeOH}$ for $5 \mathrm{~min}$, and $20 \mu \mathrm{L}$ of the centrifuged top layer were injected directly into the chromatographic system. The procedure has shown good results, making the FPSE device applicable even in cases where the matrix sampling and analysis take place at different times.

Another important innovation has been introduced by Alampanos and coworkers [83], who described the application of FPSE in human breast tissue for the determination and quantification of seven parabens (methyl paraben, ethyl paraben, propyl paraben, butyl 
paraben, isopropyl paraben, isobutyl paraben, and benzyl paraben). The breast tissue was treated as follows before the FPSE: $20-500 \mathrm{mg}$ of tissue were weighed and subsequently cut and finely ground. The resulting compound was transfected into a Falcon conical tube and vortexed with $2 \mathrm{~mL}$ of $\mathrm{AcN}$ and $2 \mathrm{~mL}$ of $\mathrm{MeOH}$ for $30 \mathrm{~s}$. It was then sonicated for $2 \mathrm{~min}$ and centrifuged at $800 \times \mathrm{g}$ for $15 \mathrm{~min}$ at room temperature. The supernatant was withdrawn. The remaining pellet was again extracted with $0.8 \mathrm{~mL}$ of $\mathrm{AcN}$ and $0.8 \mathrm{~mL}$ of $\mathrm{MeOH}$, with subsequent centrifugation at $800 \times g$ for $10 \mathrm{~min}$. The supernatant was collected and combined with the previous one, with subsequent evaporation under nitrogen flow until dryness. The final extracts were reconstituted in $1 \mathrm{~mL}$ of deionized water and considered as the sample, which underwent the subsequent process with FPSE. Among all the tested FPSE membranes, the highest extraction efficiency was achieved using sol-gel poly tetrahydrofuran (sol-gel PTHF). The extraction was performed while stirring at high speed for $35 \mathrm{~min}$, while $500 \mu \mathrm{L}$ of $\mathrm{AcN}: \mathrm{MeOH}(80: 20, \mathrm{v}: \mathrm{v})$ were applied for back-extraction for $5 \mathrm{~min}$. The eluate was evaporated until dryness under nitrogen stream for further preconcentration and reconstituted in $50 \mu \mathrm{L}$ of a mixture $\mathrm{AcN}: \mathrm{MeOH}$ $(80: 20, \mathrm{v}: \mathrm{v})$ before the chromatographic analysis. The established analytical method has been successfully applied to the bioanalysis of real samples from different volunteers (both healthy and with breast cancer). The obtained results have shown that all tested parabens were detected in $35 \%$ of the breast samples. Interestingly, the cancerous tissue samples were characterized by mean concentration values of all PBs (except for ethyl paraben) higher than those found in healthy breast tissue samples.

Mazaraki et al. [84] have reported a fast FPSE method for the isolation of $\beta$-blocker drugs (atenolol, nadolol, metoprolol, oxprenolol, labetalol, and propranolol) from human serum and urine combination with UHPLC-ESI-MS/MS. Among all tested membranes, the sol-gel CW20 M-coated FPSE membrane was identified as the best for the target $\beta$-blocker drugs. The extraction of target analytes occurred in a relatively short time $(15 \mathrm{~min})$, and the high permeability of the device permits the direct extraction of biological samples without any other pretreatment. The mixture of $\mathrm{MeOH}: \mathrm{AcN}(50: 50, \mathrm{v}: \mathrm{v})(100 \mu \mathrm{L})$ was used as an eluted system for $10 \mathrm{~min}$ (no enhancement was observed at longer desorption periods). Again, the FPSE technique has proven to be a fast, economic, and environmentally friendly sample preparation tool that offers selectivity with relatively fast extraction kinetics. The direct extraction of serum and urine samples without pretreatment (protein precipitation, etc.) has simplified and sped up the general sample preparation scheme.

Alampanos et al. [85] have reported a novel FPSE protocol for the monitoring of six bisphenol analogues (bisphenol A, bisphenol S, bisphenol F, bisphenol E, bisphenol B, bisphenol C), and diethylstilbestrol (DES) from human urine prior to HPLC-PDA analysis. The sol-gel PEG-coated FPSE membrane was selected as the best membrane for the extraction of target analytes that was carried out under stirring for $20 \mathrm{~min}$. The backextraction was performed in $\mathrm{AcN}: \mathrm{MeOH}(50: 50, \mathrm{v}: \mathrm{v})$ for 3 min under sonication. The eluate was evaporated until dryness under a nitrogen stream for extra preconcentration before the HPLC-PDA analysis. The method was applied to human urine samples, and the results showed measurable amounts of these compounds. These preliminary data demonstrate that the widespread use of BPA results in constant human overexposure and a large daily intake and that, unequivocally, there is a permanent bioaccumulation of BPA in the human body.

Recently, an innovative application of the FPSE procedure was reported by Tartaglia and coworkers [86]. In this study, a new FPSE method was applied for the extraction of phenolic compounds, including gallic acid (Gal), vanillic acid (Van), caffeic acid (Caf), syringic acid (Sir), (-)-epicatechin (Epi), p-coumaric acid (Cum), and resveratrol (Rsv) in human saliva samples.

The sol-gel CW 20M FPSE membrane ( $1 \mathrm{~cm}$ diameter) was selected as the sorbent device. The membrane, first activated in $2 \mathrm{~mL}$ of MeOH:ACN (50:50, v:v) and then washed in Milli-Q water, was directly inserted into $100 \mu \mathrm{L}$ of human saliva samples $(5 \mathrm{~min})$ for the extraction process. Back-extraction was performed in $150 \mu \mathrm{L}$ of $\mathrm{MeOH}$ for $5 \mathrm{~min}$. The 
reported extraction conditions herein applied in saliva samples have further confirmed all previous data regarding FPSE advantages.

In addition to the advantages described in the bioanalysis, an innovative application of FPSE was the evaluation as a new tool for whole blood analysis, namely the Biofluid Sampler (BFS). As described in several papers, FPSE can be applied directly to whole blood or diluted whole blood without requiring any sample pretreatment (such as filtration or protein precipitation). The FPSE technique was then pioneered as a new technique for the analysis of dried blood in order to consider the possible replacement of the traditional Dried Blood Spot with the newer FPSE (used as dried bloodstain paper), to collect whole blood samples in one place and then send them by conventional mail for analysis in certified laboratories, located elsewhere [87].

Another innovative application of the FPSE protocol was recently presented by Locatelli et al. [88]. In this work, a non-invasive in vivo FPSE sampling method was described for the analysis of exhaled breath aerosol (EBA). In particular, a fabric-phase sorptive membrane (FPSM) array was built with different devices possessing different chemistries: nonpolar sol-gel PDMS; medium-polar sol-gel PTHF, sol-gel PEG-PPG-PEG, and sol-gel PCAP-PDMS-PCAP; and polar sol-gel CW20 M and mixed-mode zwitterionic sorbent. The FPSM array, inserted inside the facemask for approximately $8 \mathrm{~h}$ (15 volunteers were included in the study), was then removed, and the extracted compounds were eluted using a mixture of $\mathrm{MeOH}$ and $\mathrm{AcN}$ containing the deuterated chemical standards. The analysis was carried out in an LC-MS/MS system, and a validated screening allowed the rapid monitoring of more than 700 compounds, with consent to extensive biomonitoring of the daily human exposure for different molecules. This study certainly represents a potential tool as a starting point for future applications of this technique for the evaluation of different potentially toxic compounds for categories of workers at risk or even to determine the levels of biomarkers from EBA.

Compared to conventional sample preparation techniques, FPSE offers ease of application, performance superiority, and reduced consumption of organic solvents. Due to the flexible nature of the FPSE membrane, it can be inserted directly into the sample solution, regardless of the complex nature of the sample matrix. The main advantages of FPSE could be summarized as follow: (i) integration of exhaustive and equilibrium extraction mechanism into a single device; (ii) availability of a wide range of adsorbents including polar, medium polar, non-polar sorbents, cation exchangers, anion exchangers, mixed-mode, zwitterionic, and mixed-mode zwitterionic; (iii) possibility of whole blood extraction without pretreatment; (iv) reduction of sample and organic solvent volume; (v) elimination of protein precipitation as a sample pretreatment process; (vi) reduction of time and cost; (vii) possibility of sampling at different times without requiring immediate analysis; (viii) possibility of non-invasive in vivo sampling.

The reported results confirm the diffusion of microextraction techniques thanks to their advantages in terms of simplicity and rapidity of the method, reduction of the consumption of organic solvents, and volume of biological samples, without losing accuracy and precision in the target analytes quantification.

\section{Conclusions}

In recent years, many methods of identification and quantification of multiple compounds in different complex biological matrices were developed and validated. An important phase of the entire analytical workflow was the extraction of target analytes from the sample according to the aim of the analysis that could be performed for both biological and forensic analyses.

This review of the literature concentrated on the work published between 2018 and 2021, highlighting the wide variety of different methods of microextraction in many biological matrices, also from postmortem origin, such as whole blood, plasma/serum, urine, oral fluid, hair, and different tissues. 
The microextraction methods demonstrated more advantages than conventional methods due to their simplicity, speed, reduction in operational time and usage of solvents, maintaining high-performance profiles for identification and quantification of target analytes, even starting from small amounts of sample.

For these reasons, the protocol reported in this review could be successfully applied to a wide range of compounds both for biological and forensic purposes.

Author Contributions: All Authors contributed equally in terms of data curation, writing, and editing. M.L.: conceptualization; M.L., C.D., V.S., H.İ.U., A.K., K.G.F. and I.A.: Supervision and Project Administration; C.D., M.B., E.R., A.T., M.L., H.İ.U., V.S., K.G.F., A.K., I.A., F.S. and U.d.G.: Writing-Original Draft Preparation; C.D., M.B., E.R., A.T., M.L., H.İ.U., V.S., K.G.F., A.K., I.A., F.S. and U.d.G.: Writing-Review \& Editing, All authors have read and agreed to the published version of the manuscript.

Funding: This review paper has not received any funding.

Institutional Review Board Statement: Not applicable.

Informed Consent Statement: Not applicable.

Data Availability Statement: Data and information are available on request to the authors.

Acknowledgments: Authors would like to thank the University "G. d'Annunzio" for the support in the literature survey.

Conflicts of Interest: The authors declare no conflict of interest.

\section{References}

1. Pourshamsi, T.; Amri, F.; Abniki, M. A comprehensive review on application of the syringe in liquidand solid phase microextraction methods. J. Iran. Chem. Soc. 2021, 18, 245-264. [CrossRef]

2. Hansen, F.A.; Pedersen-Bjergaard, S. Emerging Extraction Strategies in Analytical Chemistry. Anal. Chem. 2020, 92, 2-15. [CrossRef] [PubMed]

3. He, Y.; Concheiro-Guisan, M. Microextraction sample preparation techniques in forensic analytical toxicology. Biomed. Chromatogr. 2019, 33, e4444. [CrossRef]

4. Manousi, N.; Samanidou, V. Green sample preparation of alternative biosamples in forensic toxicology. Sustain. Chem. Pharm. 2021, 20, e100388. [CrossRef]

5. D'Ovidio, C.; Rosato, E.; Bonelli, M.; Carnevale, A.; Marsella, L.T. A particular case of accidental asphyxiation. Med. Sci. Law. 2018, 58, 55-57. [CrossRef] [PubMed]

6. D'Ovidio, C.; Bonelli, M.; Rosato, E.; Savini, F.; Carnevale, A. Evaluation of urinary catecholamines to reconstruct the individual death process after the catastrophe of Rigopiano (Italy). J. Forensic Leg. Med. 2020, 70, 101908. [CrossRef] [PubMed]

7. D'Ovidio, C.; Rosato, E.; Carnevale, A. An unusual case of murder-suicide: The importance of studying knots. J. Forensic Leg. Med. 2017, 45, 17-20. [CrossRef] [PubMed]

8. Majda, A.; Mrochem, K.; Wietecha-Posłuszny, R.; Zapotoczny, S.; Zawadzki, M. Fast and efficient analyses of the post-mortem human blood and bone marrow using DI-SPME/LC-TOF-MS method for forensic medicine purposes. Talanta 2020, 209 , e120533. [CrossRef]

9. Ahmad, S.M.; Gonçalves, O.C.; Oliveira, M.N.; Neng, N.R.; Nogueira, J.M.F. Application of Microextraction-Based Techniques for Screening-Controlled Drugs in Forensic Context-A Review. Molecules 2021, 26, 2168. [CrossRef] [PubMed]

10. Seyed, M.S.A.; Mohammad, J.K.; Zahra, M.; Maryam, A. Comparison of the Modified QuEChERS Method and the Conventional Method of Extraction in Forensic Medicine to Detect Methadone in Post-Mortem Urine by GC-MS. Asia Pac. J. Med. Toxicol. 2017, 6, 79-85. [CrossRef]

11. Locatelli, M.; Tartaglia, A.; Piccolantonio, S.; Di Iorio, L.A.; Sperandio, E.; Ulusoy, H.I.; Furton, K.G.; Kabir, A. Innovative configurations of sample preparation Techniques Applied in bioanalytical chemistry: A review. Curr. Anal. Chem. 2019, 15, 731-744. [CrossRef]

12. Sofalvi, S.; Schueler, H.E.; Lavins, E.S.; Kaspar, C.K.; Brooker, I.T.; Mazzola, C.D.; Dolinak, D.; Gilson, T.P.; Perch, S. An LC-MS/MS Method for the Analysis of Carfentanil, 3-Methylfentanyl, 2-Furanyl Fentanyl, Acetyl Fentanyl, Fentanyl and Norfentanyl in Postmortem and Impaired-Driving Cases. J. Anal. Toxicol. 2017, 41, 473-483. [CrossRef]

13. Kahl, J.H.; Gonyea, J.; Humphrey, S.M.; Hime, G.W.; Boland, D.M. Quantitative Analysis of Fentanyl and Six Fentanyl Analogs in Postmortem Specimens by UHPLC-MS/MS. J. Anal. Toxicol. 2018, 42, 570-580. [CrossRef] [PubMed]

14. Fogarty, M.F.; Papsun, D.M.; Logan, B.K. Analysis of Fentanyl and 18 Novel Fentanyl Analogs and Metabolites by LC-MS/MS, and report of Fatalities Associated with Methoxyacetylfentanyl and Cyclopropylfentanyl. J. Anal. Toxicol. 2018, 42, 592-604. [CrossRef] [PubMed] 
15. Palmquist, K.B.; Swortwood, M.J. Data-independent screening method for 14 fentanyl analogs in whole blood and oral fluid using LC-QTOF-MS. Forensic Sci. Int. 2019, 297, 189-197. [CrossRef] [PubMed]

16. Strayer, K.E.; Antonides, H.M.; Juhascik, M.P.; Daniulaityte, R.; Sizemore, I.E. LC-MS/MS-Based Method for the Multiplex Detection of 24 Fentanyl Analogues and Metabolites in Whole Blood at Sub ng mL ${ }^{-1}$ Concentrations. ACS Omega 2018, 3, 514-523. [CrossRef]

17. Truver, M.T.; Swortwood, M.J. Quantitative Analysis of Novel Synthetic Opioids, Morphine and Buprenorphine in Oral Fluid by LC-MS/MS. J. Anal. Toxicol. 2018, 42, 554-561. [CrossRef] [PubMed]

18. Smith, C.R.; Truver, M.T.; Swortwood, M.J. Quantification of U-47700 and its metabolites in plasma by LC-MS/MS. J. Chromatogr. B 2019, 1112, 41-47. [CrossRef]

19. Al-Asmari, A.I. Method for Postmortem Quantification of $\Delta 9$-Tetrahydrocannabinol and Metabolites Using LC-MS/MS. J. Anal. Toxicol. 2019, 43, 703-719. [CrossRef] [PubMed]

20. Al-Asmari, A.I. Method for the identification and quantification of sixty drugs and their metabolites in postmortem whole blood using liquid chromatography tandem mass spectrometry. Forensic Sci. Int. 2020, 309, e110193. [CrossRef]

21. Kurzweil, L.; Danyeli, L.; Şen, Z.D.; Fejtova, A.; Walter, M.; Gensberger-Reigl, S. Targeted mass spectrometry of ketamine and its metabolites cis-6-hydroxynorketamine and norketamine in human blood serum. J. Chromatogr. B 2020, 1152, e122214. [CrossRef]

22. Cui, Y.; Liu, D.; Zhao, M.; Li, J.; Yang, Y.; Li, M.; Gao, J.; Jiang, Y. A fast and simple approach for the quantification of fiveanti-hypersensitivity drugs in saliva and urine by portable ionmobility spectrometry based on magnetic graphene oxide dispersivesolid phase extraction. J. Pharm. Biomed. 2020, 189, e113414. [CrossRef]

23. Giebułtowicz, J.; Sobiech, M.; Ruzycka, M.; Lulinski, P. Theoretical and experimental approach to hydrophilic interactiondispersive solid-phase extraction of 2-aminothiazoline-4-carboxylicacid from human post-mortem blood. J. Chromatogr. A 2019, 1587, 61-72. [CrossRef]

24. Feltraco Lizot, L.; Cezimbra da Silva, A.C.; Bastiani, M.F.; Maurer, T.F.; Hahn, R.Z.; Perassolo, M.S.; Antunes, M.V.; Linden, R. Simultaneous Determination of Cocaine and Metabolites in Human Plasma Using Solid Phase Micro-Extraction Fiber Tips C18 and UPLC-MS/MS. J. Anal. Toxicol. 2020, 44, 49-56. [CrossRef]

25. Nakhodchi, S.; Alizadeh, N. Rapid simultaneous determination of ketamine and midazolam in biological samples using ion mobility spectrometry combined by headspace solid-phase microextraction. J. Chromatogr. A 2021, 1658, e462609. [CrossRef] [PubMed]

26. Song, A.; Wang, J.; Lu, G.; Jia, Z.; Yang, J.; Shi, E. Oxidized multiwalled carbon nanotubes coated fibers for headspace solid-phase microextraction of amphetamine-type stimulants in human urine. Forensic Sci. Int. 2018, 290, 49-55. [CrossRef] [PubMed]

27. Fernández, P.; González, M.; Regenjo, M.; Ares, A.M.; Fernández, A.M.; Lorenzo, R.A.; Carro, A.M. Analysis of drugs of abuse in human plasma using microextraction bypacked sorbents and ultra-high-performance liquid chromatography. J. Chromatogr. A 2017, 1485, 8-19. [CrossRef]

28. Prata, M.; Ribeiro, A.; Figueirinha, D.; Rosado, T.; Oppolzer, D.; Restolho, J.; Araújo Suzel Costa, A.R.T.S.; Barroso, M.; Gallardo, E. Determination of opiates in whole blood using microextraction bypacked sorbent and gas chromatography-tandem mass spectrometry. J. Chromatogr. A 2019, 1602, 1-10. [CrossRef]

29. Sorribes-Soriano, A.; Monedero, A.; Esteve-Turrillas, F.A.; Armenta, S. Determination of the new psychoactive substance dichloropane insaliva by microextraction by packed sorbent-Ion mobility spectrometry. J. Chromatogr. A 2019, 1603, 61-66. [CrossRef]

30. Vincenti, F.; Montesano, C.; Pirau, S.; Gregori, A.; Di Rosa, F.; Curini, R.; Sergi, M. Simultaneous Quantification of 25 Fentanyl Derivatives and Metabolites in Oral Fluid by Means of Microextraction on Packed Sorbent and LC-HRMS/MS Analysis. Molecules 2021, 26, 5870. [CrossRef] [PubMed]

31. Vejar-Vivar, C.; Bustamante, L.; Lucena, R.; Ortega, C.; Valenzuela, M.; Mardones, C. Direct coupling of MEPS to ESI-QqTOFMS for the simultaneous analysis of tricyclic antidepressants and benzodiazepines in postmortem blood. Microchem. J. 2021, 171, e106797. [CrossRef]

32. Da Cunha, K.F.; Rodrigues, L.C.; Huestis, M.A.; Costa, J.L. Miniaturized extraction method for analysis of synthetic opioids in urine by microextraction with packed sorbent and liquid chromatography-tandem mass spectrometry. J. Chromatogr. A 2020, 1624, e461241. [CrossRef]

33. Degreef, M.; van Nuijs, A.L.N.; Maudens, K.E. Validation of a simple, fast liquid chromatography-tandem mass spectrometry method for the simultaneous quantification of 40 antidepressant drugs or their metabolites in plasma. Clin. Chim. Acta 2018, 485, 243-257. [CrossRef]

34. Zawadzki, M.; Kowalski, G.; Konowałek, A.C.; Siczek, M.; Sobieszczanska, M.; Leppert, W.; Wieczorowska-Tobis, K.; Szpot, P. Rapid Determination of Sufentanil in Human Plasma by UHPLC-QqQ-MS/MS. J. Anal. Toxicol. 2021, 45, 605-611. [CrossRef] [PubMed]

35. Bombana, H.S.; dos Santos, M.F.; Munoz, D.R.; Leyton, V. Hollow-fibre liquid-phase microextraction and gas chromatographymass spectrometric determination of amphetamines in whole blood. J. Chromatogr. B 2020, 1139, e121973. [CrossRef] [PubMed]

36. Vincenti, F.; Montesano, C.; Cellucci, L.; Gregori, A.; Fanti, F.; Compagnone, D.; Curini, R.; Sergi, M. Combination of pressurized liquid extraction with dispersive liquid liquid micro extraction for the determination of sixty drugs of abuse in hair. J. Chromatogr. A 2019, 1605, e360348. [CrossRef] [PubMed] 
37. Mercieca, G.; Odoardi, S.; Cassar, M.; Rossi, S.S. Rapid and simple procedure for the determination of cathinones, amphetaminelike stimulants and other new psychoactive substancesin blood and urine by GC-MS. J. Pharm. Biomed. 2018, 149, 494-501. [CrossRef] [PubMed]

38. Temerdashev, A.; Dmitrieva, E.; Azaryan, A.; Gashimova, E. A novel approach to the quantification of urinary arylpropionamidederived SARMs by UHPLC-MS/MS. Biomed. Chromatogr. 2020, 34, e4700. [CrossRef] [PubMed]

39. De Boeck, M.; Dubrulle, L.; Dehaen, W.; Tytgat, J.; Cuypers, E. Fast and easy extraction of antidepressants from whole blood using ionic liquids as extraction solvent. Talanta 2018, 180, 292-299. [CrossRef] [PubMed]

40. De Boeck, M.; Dehaen, W.; Tytgat, J.; Cuypers, E. Ionic Liquid-Based Liquid-Liquid Microextraction for Benzodiazepine Analysis in Postmortem Blood Samples. J. Forensic Sci 2018, 63, 1875-18709. [CrossRef] [PubMed]

41. Vårdal, L.; Wong, G.; Øiestad, A.M.L.; Pedersen-Bjergaard, S.; Gjelstad, A.; Øiestad, E.L. Rapid determination of designer benzodiazepines, benzodiazepines, and Z-hypnotics in whole blood using parallel artificial liquid membrane extraction and UHPLC-MS/MS. Anal. Bioanal. Chem. 2018, 410, 4967-4978. [CrossRef]

42. Ask, K.S.; Lid, M.; Øiestad, E.L.; Pedersen-Bjergaard, S.; Gjelstad, A. Liquid-phase microextraction in 96-well plates-calibration and accurate quantification of pharmaceuticals in human plasma samples. J. Chromatogr. A 2019, 1602, 117-123. [CrossRef] [PubMed]

43. Orfanidis, A.; Gika, H.G.; Theodoridis, G.; Mastrogianni, O.; Raikos, N. A UHPLC MS-MS Method for the Determination of 84 Drugs of Abuse and Pharmaceuticals in Blood. J. Anal. Toxicol. 2021, 45, 28-43. [CrossRef]

44. De Boeck, M.; Missotten, S.; Dehaen, W.; Tytgat, J.; Cuypers, E. Development and validation of a fast ionic liquid-based dispersive liquid-liquid microextraction procedure combined with LC-MS/MS analysis for the quantification of benzodiazepines and benzodiazepine-like hypnotics in whole blood. Forensic Sci. Int. 2017, 274, 44-54. [CrossRef]

45. Caspar, A.T.; Kollas, A.B.; Maurer, H.H.; Meyer, M.R. Development of a quantitative approach in blood plasma for low-dosed hallucinogens and opioids using LC-high resolution mass spectrometry. Talanta. 2018, 176, 635-645. [CrossRef]

46. Rocchi, R.; Simeoni, M.C.; Montesano, C.; Vannutelli, G.; Curini, R.; Sergi, M.; Compagnone, D. Analysis of new psychoactive substances in oral fluids by means of microextraction by packed sorbent followed by ultra-high performance liquid chromatography-tandem mass spectrometry. Drug Test. Anal. 2018, 10, 865-873. [CrossRef]

47. Shoff, E.N.; Zaney, M.E.; Kahl, J.H.; Hime, G.W.; Boland, D.M. Qualitative Identification of Fentanyl Analogs and Other Opioids in Postmortem Cases by UHPLC-Ion Trap-MSn. J. Anal. Toxicol. 2017, 41, 484-492. [CrossRef] [PubMed]

48. Lin, Z.; Li, J.; Zhang, X.; Qiu, M.; Huang, Z.; Rao, Y. Ultrasound-assisted dispersive liquid-liquid microextraction for thedetermination of seven recreational drugs in human whole blood using gas chromatography-mass spectrometry. J. Chromatogr. B 2017, 1046, 177-184. [CrossRef]

49. Rodrigues, T.B.; Morais, D.R.; Gianvecchio, V.A.P.; Aquino, E.M.; Cunha, R.L.; Huestis, M.A.; Costa, J.L. Development and Validation of a Method for Quantification of 28 Psychotropic Drugs in Postmortem Blood Samples by Modified Micro-QuEChERS and LC-MS-MS. J. Anal. Toxicol. 2021, 45, 644-656. [CrossRef]

50. Scheid, C.; Eller, S.; Oenning, A.L.; Carasek, E.; Merib, J.; De Oliveira, T.F. Application of Homogeneous Liquid-Liquid Microextraction with Switchable Hydrophilicity Solvents to the Determination of MDMA, MDA and NBOMes in Postmortem Blood Samples. J. Anal. Toxicol. 2021, bkab100, IN PRESS. [CrossRef] [PubMed]

51. Pouliopoulos, A.; Tsakelidou, E.; Krokos, A.; Gika, H.G.; Theodoridis, G.; Raikos, N. Quantification of 15 Psychotropic Drugs in Serum and Postmortem Blood Samples after a Modified Mini-QuEChERS by UHPLC-MS-MS. J. Anal. Toxicol. 2018, 42, 337-345. [CrossRef]

52. Pires da Silva, C.; Dal Piaz, L.P.P.; Gerbase, F.E.; Vendramini Müller, V.; Lima Feltraco Lizot, L.; Venzon Antunes, M.; Linden, R. Simple extraction of toxicologically relevant psychotropic compounds and metabolites from whole blood using mini-QuEChERS followed by UPLC-MS/MS analysis. Biomed. Chromatogr. 2021, 35, e5142. [CrossRef]

53. Kusano, M.; Sakamoto, Y.; Natori, Y.; Miyagawa, H.; Tsuchihashi, H.; Ishii, A.; Zaitsu, K. Development of "Quick-DB forensic": A total workflow from QuEChERS-dSPE method to GC-MS/MS quantification of forensically relevant drugs and pesticides in whole blood. Forensic Sci. Int. 2019, 300, 125-135. [CrossRef] [PubMed]

54. Campêlo, J.M.; Rodrigues, T.B.; Costa, J.L.; Santos, J.M. Optimization of QuEChERS extraction for detection and quantification of 20 antidepressants in postmortem blood samples by LC-MS/MS. Forensic Sci. Int. 2021, 319, 110660. [CrossRef] [PubMed]

55. Li, Y.S.; Petrikovics, I.; Yu, J. Performance comparison between solid phase extraction and magnetic carbon nanotubes facilitated dispersive-micro solid phase extractions (Mag-CNTs/d- $\mathrm{SPE}$ ) of a cyanide metabolite in biological samples using GC-MS. J. Anal. Sci Technol. 2021, 12, 42. [CrossRef]

56. Accioni, F.; García-Gómez, D.; Girela, E.; Rubio, S. SUPRAS extraction approach for matrix-independent determination of amphetamine-type stimulants by LC-MS/MS. Talanta 2018, 182, 574-582. [CrossRef]

57. Gallo, V.; Tomai, P.; Di Lisio, V.; Dal Bosco, C.; D'Angelo, P.; Fanali, C.; D’Orazio, G.; Silvestro, I.; Picó, Y.; Gentili, A. Application of a Low Transition Temperature Mixture for the Dispersive Liquid-Liquid Microextraction of Illicit Drugs from Urine Samples. Molecules 2021, 26, 5222. [CrossRef] [PubMed]

58. Tomai, P.; Gentili, A.; Curini, R.; Gottardo, R.; Tagliaro, F.; Fanali, S. Dispersive liquid-liquid microextraction, an effective tool for the determination of synthetic cannabinoids in oral fluid by liquid chromatography tandem mass spectrometry. J. Pharm. Anal. 2021, 11, 292-298. [CrossRef] [PubMed] 
59. Shishov, A.Y.; Chislov, M.V.; Nechaeva, D.V.; Moskvin, L.N.; Bulatov, A.V. A new approach for microextraction of non-steroidal anti-inflammatory drugs from human urine samples based on in-situ deep eutectic mixture formation. J. Mol. Liq. 2018, 272, 738-745. [CrossRef]

60. Zamani, F.; Farajmand, B.; Yaftian, M.R. Corona discharge ion mobility spectrometry combined by homogenizer assisted dispersive liquid-phase microextraction; A rapid and sensitive method for quantification of nortriptyline. Microchem. J. 2020, 159, e105540. [CrossRef]

61. Barati, E.; Alizadeh, N. Simultaneous determination of sertraline, imipramine and alprazolam in human plasma samples using headspace solid phase microextraction based on a nanostructured polypyrrole fiber coupled to ion mobility spectrometry. Anal. Methods 2020, 12, 930-937. [CrossRef]

62. Khelfi, A.; Azzouz, M.; Abtroun, R.; Reggabi, M.; Alamir, B. Determination of Chlorpromazine, Haloperidol, Levomepromazine, Olanzapine, Risperidone, and Sulpiride in Human Plasma by Liquid Chromatography/Tandem Mass Spectrometry (LC-MS/MS). Int. J. Anal. Chem. 2018, 2018, e5807218. [CrossRef] [PubMed]

63. Degreef, M.; Berry, E.M.; Maudens, K.E.K.; van Nuijs, A.L.N. Multi-analyte LC-MS/MS quantification of 38 antipsychotics and metabolites in plasma: Method validation \& application to routine analyses. J. Chromatogr. B 2021, 1179, e122867. [CrossRef]

64. Locatelli, M.; Tinari, N.; Grassadonia, A.; Tartaglia, A.; Macerola, D.; Piccolantonio, S.; Sperandio, E.; D'Ovidio, C.; Carradori, S.; Ulusoy, H.I.; et al. FPSE-HPLC-DAD method for the quantification of anticancer drugs in human whole blood, plasma, and urine. J. Chromatogr. B 2018, 1095, 204-213. [CrossRef] [PubMed]

65. Rochani, A.; Lam, E.; Tanjuakio, J.; Hirose, H.; Kraft, W.K.; Kaushal, G. Simultaneous quantitative LC-MS method of ketamine, midazolamand their metabolites (dehydronorketamine, norketamine and 1hydroxymidazolam) for its application in patients on extracorporealmembrane oxygenation (ECMO) therapy. J. Pharm. Biomed. 2020, 178, e112947. [CrossRef]

66. Sun, S.; Wang, Y.; Liu, X.; Fu, R.; Yang, L. Rapid and sensitive tapered-capillary microextraction combined to on-line sample stacking-capillary electrophoresis for extraction and quantification of two beta-blockers in human urine. Talanta 2018, 180, 90-97. [CrossRef]

67. Nazdrajić, E.; Tascon, M.; Rickert, D.A.; Gómez-Ríos, G.A.; Kulasingam, V.; Pawliszyn, J.B. Rapid determination of tacrolimus and sirolimus in whole human blood by direct coupling of solid-phase microextraction to mass spectrometry via microfluidic open interface. Anal. Chim. Acta 2021, 1144, 53-60. [CrossRef]

68. Locatelli, M.; Kabir, A.; Innosa, D.; Lopatriello, T.; Furton, K.G. A fabric phase sorptive extraction-High performance liquid chromatography-Photo diode array detection method for the determination of twelve azole antimicrobial drug residues in human plasma and urine. J. Chromatogr. B 2017, 1040, 192-198. [CrossRef]

69. Hasan, M.; Hofstetter, R.; Fassauer, G.M.; Link, A.; Siegmund, W.; Oswald, S. Quantitative chiral and achiral determination of ketamine and itsmetabolites by LC-MS/MS in human serum, urine and fecal samples. J. Pharm. Biomed. Anal. 2017, 139, 87-97. [CrossRef]

70. Jouyban, A.; Farajzadeh, M.A.; Mogaddam, M.R.A.; Khodadadeian, F.; Nemati, M.; Khoubnasabjafari, M. In-situ formation of a hydrophobic deep eutectic solvent based on alpha terpineol and its application in liquid-liquid microextraction of three $\beta$-blockers from plasma samples. Microchem. J. 2021, 170, e106687. [CrossRef]

71. Šlampova, A.; Kubaň, P. Two-phase micro-electromembrane extraction with a floating drop free liquid membrane for the determination of basic drugs in complex samples. Talanta 2020, 206, 120255. [CrossRef]

72. Kumar, R.; Gaurav; Heena; Malik, A.K.; Kabir, A.; Furton, K.G. Efficient analysis of selected estrogens using fabric phase sorptiveextraction and high-performance liquid chromatography-fluorescence detection. J. Chromatogr. A 2014, 1359, 16-25. [CrossRef]

73. Guedes-Alonso, R.; Ciofi, L.; Sosa-Ferrera, Z.; Santana-Rodríguez, J.J.; del Bubba, M.; Kabir, A.; Furton, K.G. Determination of androgens and progestogens in environmental andbiological samples using fabric phase sorptive extraction coupled toultra-high performance liquid chromatography tandem massspectrometry. J. Chromatogr. A 2016, 1437, 116-126. [CrossRef]

74. Samanidou, V.; Kaltzi, I.; Kabir, A.; Furton, K.G. Simplifying sample preparation using fabric phase sorptive extraction technique for the determination of benzodiazepines in blood serum by high-performance liquid chromatography. Biomed. Chromatogr. 2016, 30, 829-836. [CrossRef]

75. Kabir, A.; Furton, K.G.; Tinari, N.; Grossi, L.; Innosa, D.; Macerola, D.; Tartaglia, A.; Di Donato, V.; D’Ovidio, C.; Locatelli, M. Fabric phase sorptive extraction-high performance liquid chromatography photo diode array detection method for simultaneous monitoring of three inflammatory bowel disease treatment drugs in whole blood, plasma, and urine. J. Chromatogr. B 2018, 1084, 53-63. [CrossRef] [PubMed]

76. Locatelli, M.; Furton, K.G.; Tartaglia, A.; Sperandio, E.; Ulusoy, H.I.; Kabir, A. An FPSE-HPLC-PDA method for rapid determination of solar UV filters in human whole blood, plasma, and urine. J. Chromatogr. B 2019, 1118-1119, 40-50. [CrossRef]

77. Tartaglia, A.; Kabir, A.; Ulusoy, S.; Sperandio, E.; Piccolantonio, S.; Ulusoy, H.I.; Furton, K.G.; Locatelli, M. FPSE-HPLC-PDA analysis of seven paraben residues in human whole blood, plasma, and urine. J. Chromatogr. B 2019, 1125, 121707. [CrossRef] [PubMed]

78. Alampanos, V.; Kabir, A.; Furton, K.G.; Samanidou, V. Magnet integrated fabric phase sorptive extraction of selected endocrine disrupting chemicals from human urine followed by high-performance liquid chromatography-photodiode array analysis. $J$. Chromatogr. B 2021, 1654, e462459. [CrossRef] 
79. Parla, A.; Zormpa, E.; Paloumpis, N.; Kabir, A.; Furton, K.G.; Roje, Z.; Samanidou, V.; Vrcek, I.V.; Panderi, I. Determination of Intact Parabens in the Human Plasma of Cancer and Non-Cancer Patients Using a Validated Fabric Phase Sorptive Extraction Reversed-Phase Liquid Chromatography Method with UV Detection. Molecules 2021, 26, 1526. [CrossRef] [PubMed]

80. Lioupi, A.; Kabir, A.; Furton, K.G.; Samanidou, V. Fabric phase sorptive extraction for the isolation of five common antidepressants from human urine prior to HPLC-DAD analysis. J. Chromatogr. B 2019, 1118-1119, 171-179. [CrossRef]

81. Alampanos, V.; Kabir, A.; Furton, K.G.; Samanidou, V.; Papadoyannis, I. Fabric phase sorptive extraction for simultaneous observation of four penicillin antibiotics from human blood serum prior to high performance liquid chromatography and photo-diode array detection. Microchem. J. 2019, 149, e103964. [CrossRef]

82. Tartaglia, A.; Kabir, A.; D’Ambrosio, F.; Ramundo, P.; Ulusoy, S.; Ulusoy, H.I.; Merone, G.M.; Savini, F.; D'Ovidio, C.; de Grazia, U.; et al. Fast off-line FPSE-HPLC-PDA determination of six NSAIDs in saliva samples. J. Chromatogr. B 2020, 1144 , e122082. [CrossRef]

83. Alampanos, V.; Kabir, A.; Furton, K.G.; Roje, Z.; Vrcek, I.V.; Samanidou, V. Fabric phase sorptive extraction combined with high-performance-liquid chromatography-photodiode array analysis for the determination of seven parabens in human breast tissues: Application to cancerous and non-cancerous samples. J. Chromatogr. A 2020, 1630, e461530. [CrossRef] [PubMed]

84. Mazaraki, K.; Kabir, A.; Furton, K.G.; Fytianos, K.; Samanidou, V.; Zacharis, C.K. Fast fabric phase sorptive extraction of selected $\beta$-blockers from human serum and urine followed by UHPLC-ESI-MS/MS analysis. J. Pharm. Biomed. 2021, 199, e114053. [CrossRef] [PubMed]

85. Alampanos, V.; Kabir, A.; Furton, K.G.; Samanidou, V. Rapid exposure monitoring of six bisphenols and diethylstilbestrol in human urine using fabric phase sorptive extraction followed by high performance liquid chromatography-photodiode array analysis. J. Chromatogr. B 2021, 1177, e122760. [CrossRef] [PubMed]

86. Tartaglia, A.; Romasco, T.; D'Ovidio, C.; Rosato, E.; Ulusoy, H.I.; Furton, K.G.; Kabir, A.; Locatelli, M. Determination of phenolic compounds in human saliva after oral administration of red wine by high performance liquid chromatography. J. Pharm. Biomed. 2021, 209, e114486. [CrossRef] [PubMed]

87. Locatelli, M.; Tartaglia, A.; D'Ambrosio, F.; Ramundo, P.; Ulusoy, H.I.; Furton, K.G.; Kabir, A. Biofluid sampler: A new gateway for mail-in-analysis of whole blood samples. J. Chromatogr. B 2020, 1143, e122055. [CrossRef] [PubMed]

88. Locatelli, M.; Tartaglia, A.; Ulusoy, H.I.; Ulusoy, S.; Savini, F.; Rossi, S.; Santavenere, F.; Merone, G.M.; Bassotti, E.; D’Ovidio, C.; et al. Fabric-Phase Sorptive Membrane Array as a Noninvasive In Vivo Sampling Device for Human Exposure to Different Compounds. Anal. Chem. 2021, 93, 1957-1961. [CrossRef] 